\title{
Autocrined leptin promotes proliferation of non-small cell lung cancer (NSCLC) via PI3K/AKT and p53 pathways
}

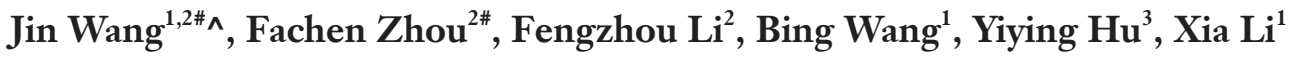 \\ ${ }^{1}$ Department of Immunology, Dalian Medical University, Dalian, China; ${ }^{2}$ Department of Thoracic Surgery, the First Affiliated Hospital of Dalian \\ Medical University, Dalian, China; ${ }^{3}$ Department of Neuroelectrophysiology, the First Affiliated Hospital of Dalian Medical University, Dalian, China \\ Contributions: (I) Conception and design: X Li; (II) Administrative support: None; (III) Provision of study materials or patients: J Wang, F Zhou. (III) \\ Collection and assembly of data: J Wang, F Zhou, F Li, B Wang; (IV) Data analysis and interpretation: J Wang, Y Hu; (V) Manuscript writing: All \\ authors; (VI) Final approval of manuscript: All authors. \\ "These authors contributed equally to this work and are co-first authors. \\ Correspondence to: Xia Li. Department of Immunology, Dalian Medical University, Dalian, China. Email: lixia416@163.com.
}

Background: Circulating leptin can directly act on tumor cells. However, a recent meta-analysis showed that plasma leptin concentration had no significant effect on the survival of lung cancer patients. So does Leptin have an effect on lung cancer? Or there may be other factors that influence the effect.

Methods: Genome sequencing database Oncomine was searched to learn the differential expression of leptin between tumors and normal lungs. Fresh tumor specimens and paired normal lung tissue from six lung adenocarcinoma patients were collected, and validate the expression level of leptin. Clinicopathological information and tumor slices from 60 non-small cell lung cancer (NSCLC) patients were analyzed to evaluate the prognostic value of autocrined leptin. Whole genome sequencing data from the cancer genome atlas (TCGA) was analyzed to predict the underlying mechanism of leptin regulating tumor proliferation. Finally, these findings were confirmed by using cell lines H1299, A549, H460, and H322 to explore the promoting effect and mechanism of leptin on cell proliferation in vitro.

Results: Five datasets in Oncomine reported the expression of the LEP gene in NSCLC, and 4 datasets showed that leptin was up-regulated in tumors compared with normal lungs. Leptin was also overexpressed in 5 out of 6 clinical lung adenocarcinoma specimens. The analysis of the 60 NSCLC patients revealed that autocrined leptin could serve as an auxiliary prognostic factor, and a higher expression of leptin indicated a higher survival risk. Gene set enrichment analysis (GSEA) showed that the PI3K/AKT/mTOR signaling pathway was positively enriched when the LEP gene was highly expressed, while the P53 signaling pathway was negatively enriched. Leptin promoted cell cycle and clone formation in H1299 and A549 cells, upregulation or down-regulation of leptin in these two cell lines led to enhanced or declined proliferation. Finally, it was confirmed that the $P I 3 K / A K T / m T O R$ signaling pathway was positively regulated by leptin expression, while the $P 53$ signaling pathway was negatively regulated.

Conclusions: Autocrined leptin was observed in majority of NSCLC tissue, which could serve as an auxiliary prognostic factor for NSCLC patients. Autocrined leptin had a promoting effect on the proliferation of NSCLC cells, which probably positively regulating the PI3K/AKT/mTOR signaling pathway and negatively regulate the $P 53$ signaling pathway.

Keywords: Leptin; non-small cell lung cancer (NSCLC); PI3K/AKT; p53

Submitted Sep 04, 2020. Accepted for publication Apr 04, 2021.

doi: 10.21037/atm-20-7482

View this article at: http://dx.doi.org/10.21037/atm-20-7482

\footnotetext{
^ ORCID: 0000-0001-5527-0102.
} 


\section{Introduction}

During cancer development, the interaction between cancer-promoting factors, and cancer-inhibiting is complicated, but in general, cancer is a systemic disease, and not a disease restricted only to its cancerous organs (1). There is a long history of exploration of the systemic risk of cancer, an important area of which is the impact of internal secretion systems on cancer. From this perspective, cancer can be thought of as an endocrine disease, with its occurrence and development being regulated by the systemic endocrine signal. These signals are usually produced by specific tissues or cells that produce and secrete peptide hormones, which are transported by blood circulation to distant target cells (2). Hundreds of cancerrelated hormones have been identified and studied thus far, the most important of which include sex hormones, glucocorticoids, melatonin, growth hormone, thyroid hormone, gonadotropin, and pituitary hormone (3).

Adipose tissue has long been thought to be simply the tissue in the body that stores energy, but with the discovery of adiponectin, omentin, visfatin and other hormones secreted by adipose tissue, the fact that adipose tissue is an active secretory tissue in the body has been gradually accepted $(4,5)$. Leptin, which was first discovered in 1994, is a protein hormone secreted by adipose tissue and a polypeptide product encoded by the leptin gene (LEP) located on chromosome 6 in mice and chromosome 7 in humans. Leptin is similar to some interleukins (IL-6) in molecular structure (6). The discovery of leptin led to the identification of the role of adipose tissue in nutrition and immunity (7). Its two primary functions were initially identified: (I) reduction of appetite for the central nervous system (CNS) action; (II) lipodecomposition activity on peripheral tissues, and the stimulation of the oxidation of fatty acids, so as to prevent the accumulation of fat (8) and fatty acids.

In the blood, leptin appears in its free form, which can bind to a receptor (Ob-R) on targetable cell membrane. Subsequent studies have confirmed that this endocrine and paracrine active adipokine is mainly produced by adipose tissue, but is also present in gastric mucosa, skeletal muscle, breast epithelium, placenta, bone marrow, pituitary gland tissue, and osteoblasts (9).

In recent years, more and more studies have shown that leptin plays an important role in tumor progression. Adipocyte homeostasis depends on leptin, and resistance to leptin leads to adipotoxicity and apoptosis of cellular fat, which increase the risk of neoplasia (10). When the leptin signaling is impaired, the excess fat is stored in nonadipose tissue and oxidized. As a result, these cells are exposed to large amounts of lipid metabolites, such as ceramides, nitric oxide, and peroxides, which can cause lipid breakdown or tumorigenesis (11). In addition to the consequences of impaired leptin activity, it can be directly attributed to its ability to stimulate cell proliferation.

The increased concentration of leptin in the blood is closely related to the decline of the long-term prognosis of patients with various malignancies, including breast cancer $(12,13)$, colon cancer $(14,15)$, prostate cancer $(16)$, thyroid cancer (17), and ovarian cancer $(13,16)$. Further studies have shown that leptin, produced by fat cells and secreted into the blood, acts on tumor cells in an endocrine manner, by activating a series of signaling pathways in cells, including 7AK/STAT3, PI3K/AKT, MAPK/ERK, and insulin receptor pathways. These pathways are closely related to cancer proliferation, invasion, and metastasis, which are activated by leptin through its receptor (Ob-R) on the tumor cell surface, and promote tumor progression, worsening the long-term prognosis of patients (18-20).

Previous studies have shown that leptin facilitates the growth of malignant tumors such as breast cancer, colon cancer, and prostate cancer. Multiple reports from in vitro studies have shown that leptin has a promotive impact on the proliferation, metastasis, and angiogenesis of lung cancer. However, a recent meta-analysis showed that plasma leptin concentrations had no significant effect on long-term outcome in patients with lung cancer (18). Several studies have shown that leptin and its receptor are overexpressed in NSCLC, and leptin protein is mainly expressed in the cytoplasm of epithelial cells (cancer cells) and the expression level is higher than that of normal lung tissues, while Ob-R is expressed in both cytoplasm and the membrane of tumor cells (18,19,21-27). Thus, whether leptin promotes the proliferation of lung cancer remains unclear. Since leptin concentration in the plasma of patients with lung cancer is not in accordance with the prognosis of lung cancer. In the current study, we assume that leptin acts on NSCLC cells most probably through an autocrine manner. We assume that leptin acts on NSCLC cells most probably through an autocrine manner, and further explore the molecular mechanism of its carcinogenic effect by which autocrined leptin promotes the proliferation of NSCLC.

We present the following article in accordance with the MDAR checklist (available at http://dx.doi.org/10.21037/ 
atm-20-7482).

\section{Methods}

\section{Case selection}

\section{Sample one}

Tumor tissue samples and normal lung tissue samples of six patients with different pathological subtypes of lung adenocarcinoma were collected to observe the differential expression of $L E P$. These six patients undergone thoracoscopic lobectomy at the First Affiliated Hospital of Dalian Medical University in June 2019, and all surgical specimens were immediately immersed in liquid nitrogen after resection.

\section{Sample two}

This study retrospectively collected a total of 60 clinical and pathological specimens from patients with stage II to III (the 7th TNM stage) lung adenocarcinoma who underwent thoracoscopic lobectomy at the First Affiliated Hospital of Dalian Medical University from June to December 2012. There were 29 males and 31 females enrolled, and the age ranged from 37 to 76 years old. Criteria for inclusion of patients into the study were the following: diagnosed by positron emission tomography (PET) or computed tomography (CT), with no contralateral lymph node enlargement or distant metastasis; no chemoradiotherapy before surgery; intraoperative pathological examination showing lung cancer and no tumor cells in the residual margin; systemic lymphadenectomy during operation. All cases included had complete clinical data, including age, gender, degree of tissue differentiation, TNM stage, invasive situation, and other clinicopathological features. All patients received four cycles of chemotherapy with a platinum and pemetrexed plan. The study was approved by the Ethics Committee of the First Affiliated Hospital of Dalian Medical University (No.: PJ-KS-KY-2021-39), and all participants signed written informed consent forms. This study conformed to the provisions of the Declaration of Helsinki (as revised in 2013).

All patients were followed up every 3 months in 1 year after operation, and then every half a year; follow-up included physical examination, chest CT scan, and tumor marker examination. Overall survival (OS) was defined as the time from the diagnosis of the disease until the death of the patient or the end of follow-up. For each patient, the follow-up period was 60 months, and we censored information from patients who were lost to follow-up or who died from causes other than lung cancer. Disease-free survival (DFS) was defined as the time from the patient's surgery until the first diagnosis of tumor recurrence.

\section{Cell lines and plasmids}

Human lung adenocarcinoma cells H1299, A549, H460, and H322, human embryo lung fibroblasts (HLF), and human bronchial epithelial (HBE) cells, were all acquired from the American Type Culture Collection (ATCC).

Four plasmids containing the short hairpin RNA (shRNA) sequence for the $L E P$ gene and one containing the open reading frame (ORF) for the $L E P$ gene were included. The full-length plasmids were obtained from the human gene library of the Institute of Cancer Stem Cells, Dalian Medical University. The sequence of the four shRNA fragments were as follows: sh1 5'-TGGAAGCACATGTTTATTT-3', sh 2 5'-TGCTTGAAACCAAAGATAT-3', sh 3 5 ' - AAGTCCAAGATGACACCAA-3', and sh 4 5'-AGGACCAGGTTATTTTAAA-3'. The specific steps of lentivirus packaging have been described previously (28).

\section{Antibodys and reagents}

Rabbit anti-human leptin monoclonal antibody was purchased from Bioss Antibodies (Woburn, MA, USA); rabbit anti-human LC3, $\beta$-actin, and P62 monoclonal antibodies were purchased from Proteintech; rabbit antihuman $\mathrm{Ob}-\mathrm{R}$ monoclonal antibodies were purchased from Shenyang Wanlei Biological Company (Shenyang, China); Rabbit anti-human $A K T, p-A K T, p-E R K, p-N F-\kappa B, p 65$, cyclin D1, CDK2, p53, MDM2, p-MDM2, and p-mTOR monoclonal antibodies were purchased from Cell Signaling Technology (CST, Danvers, MA, USA).

\section{Immunohistochemical (IHC) studies}

IHC staining was carried out according to the methods previously reported, and to observe the amount and location of leptin expression.

\section{Western blotting}

The total proteins of four non-small cell lung cancer (NSCLC) cell lines, H1299, A549, H460, and H322, and the control cell line, HLF, were analyzed by western blotting.

\section{Protein immunofluorescence staining}

Protein immunofluorescence was used to detect the effect of endogenous leptin expression level on the expression level of 
A

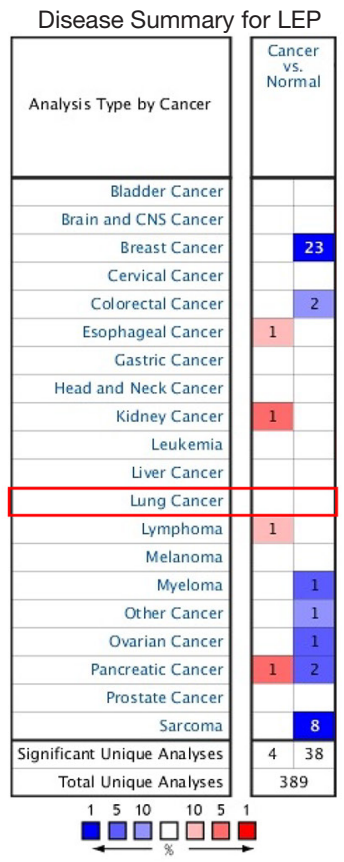

B
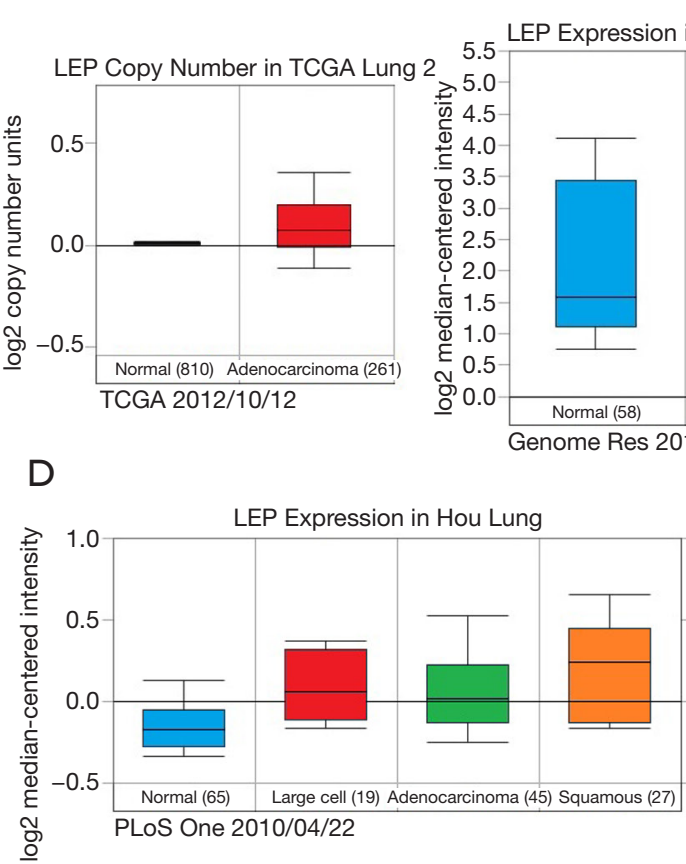

C

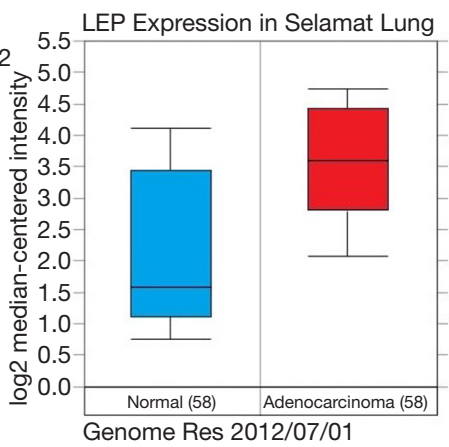

E

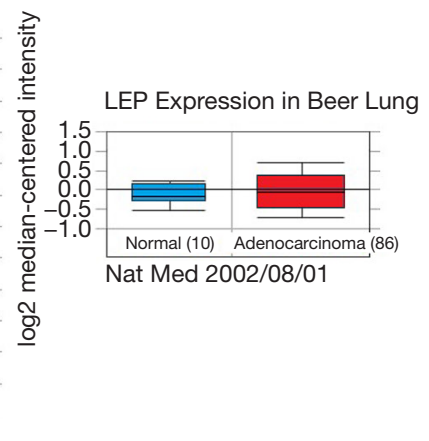

$\mathrm{F}$

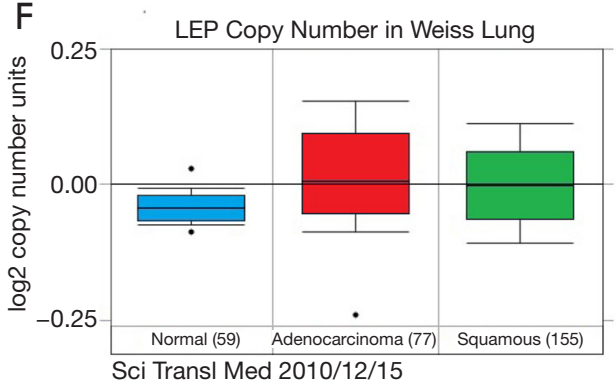

Cell color is determined by the best gene rank percentile for the analyses within the cell. NOTE: An analysis may be counted in more than one cancer type.

G
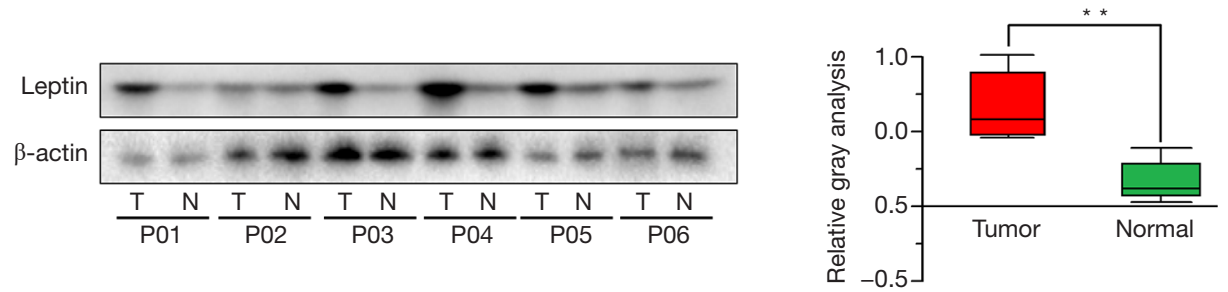

Figure 1 Analysis of differential LEP gene and leptin expression in lung cancer and normal lung tissue. (A) An overview of 389 Oncomine gene sequencing datasets: 38 datasets reported low LEP gene expression in cancer tissues, and 4 reported high LEP gene expression in cancer tissues; leptin showed weaker expression in breast cancer, colon cancer, sarcoma, and other malignant tumors. (B) The LEP gene was highly expressed in 261 lung adenocarcinoma specimens in the Oncomine TCGA Lung dataset (compared to 810 normal lung tissue specimens). (C) The LEP gene in the Oncomine Selamat Lung dataset was highly expressed in 58 Lung adenocarcinoma specimens (compared to 58 normal lung tissue specimens from corresponding patients). (D) The LEP gene was highly expressed in 58 lung adenocarcinoma specimens in the Oncomine Hou Lung dataset (compared to 58 normal tissue specimens and 46 other pathological lung cancer tissue samples). (E) The LEP gene in the Oncomine Beer Lung dataset was highly expressed in 86 Lung adenocarcinoma specimens (compared to 10 normal tissue specimens). (F) The LEP gene in the Oncomine Weiss Lung dataset was highly expressed in 77 lung adenocarcinoma samples (compared with 59 normal tissue samples and 155 lung squamous cell carcinoma tissue samples). (G) Western blotting was used to compare leptin expression levels of 6 patients' lung adenocarcinoma tissues with different pathological subtypes and normal control lung tissues (Sample one); the results showed that leptin was overexpressed in lung adenocarcinoma tissues in 5 patients (compared to normal control lung tissues). ${ }^{* *}, \mathrm{P}$ value $\leq 0.01$ ( $t$-test). 
autophagy-related protein, LC3-II, in H1299 cell lines.

\section{Bioinformatics}

The Oncomine database(https://www.oncomine.org/) was used to determine the differential expression of the LEP gene between lung cancer and normal lung tissue. After logging into the database, "LEP (GENE)" was input into the search bar to query the LEP GENE Summary View. In the overview interface, the retrieval condition of LEP GENE was set as the following: (I) GENE $=L E P$; (II) Threshold $(P$ value $)=0.05$; (III) Threshold (Fold Change) =1.5; (IV) Threshold (Gene Rank) =10\%; (V) Data Type = ALL; (VI) Analysis Type = Cancer vs. Normal Analysis. An overview of $L E P$ gene expression in different cancer types was thus retrieved. The expression of $L E P$ in lung cancer tissues and normal lung tissues in different data sets was analyzed, and a box chart was drawn with $\log 2$ (expression amount) as the vertical coordinate to visually show the differential expression of the $L E P$ gene in lung cancer tissues and normal lung tissues.

Complete transcriptome expression data of all 524 patients with lung adenocarcinoma in the database were downloaded from the official website of The Cancer Genome Atlas (TCGA) (https://www.cancer.gov/) for this study. The original data contained messenger RNA (mRNA) expression levels of more than 19,000 defined genes of these patients.

We performed gene set enrichment analysis (GSEA) using the whole genome sequencing data of lung adenocarcinoma patients from TCGA. The Kyoto Encyclopedia of Genes and Genomes (KEGG) was used to map gene pathways. The R language "limma" package was used to calculate the differential expression of genes in 524 lung adenocarcinoma tissues. The "clusterProfiler" package was used for enrichment analysis and visualization of genes significantly co-expressed with the LEP gene, and a P value $<0.05$ was considered statistically significant. A gene heat map was used to describe the expression of $L E P$ gene in cell signaling pathway. The relationship between the gene expression in cell signaling pathway and the LEP gene expression was described by a gene heat map.

\section{RT-PCR}

Reverse transcription polymerase chain reaction (RT-PCR) was used to detect the expression of LEP mRNA in four human lung adenocarcinoma cell lines and two control cell lines. Total RNA was extracted by Trizol method, and the reverse transcription system was performed according to the instructions of a reverse transcription kit, at $37^{\circ} \mathrm{C}$ for $3 \mathrm{~min}$. The first strand of complementary DNA (cDNA) was synthesized at $85^{\circ} \mathrm{C}$ for $5 \mathrm{~s}$. The chain reaction amplification system was prepared according to the instructions of the PCR integrated reagent. The reaction procedure was 30 cycles of the following: $95^{\circ} \mathrm{C}$ for $3 \mathrm{~min}, 94^{\circ} \mathrm{C}$ for $30 \mathrm{~s}$, $60{ }^{\circ} \mathrm{C}$ for $30 \mathrm{~s}$, and $68^{\circ} \mathrm{C}$ for $120 \mathrm{~s}$. After the reaction, agarose gel electrophoresis was used to detect the DNA bands and analyze the results. The leptin gene primer sequence was the following: F, ATGCATTGGGGAACCCTGTGCGG; R, TGAGGTCCAGCTGCCACAGCATG.

\section{Flow cytometry analysis}

Flow cytometry apoptosis test with annexin V-FITC/ propidium iodide (AV/PI) staining was used to detect the effect of endogenous leptin expression in H1299 and A549 cells on the apoptosis of lung adenocarcinoma cells. The cells to be tested were inoculated in a $10 \mathrm{~cm}$ petri dish, and the cells were allowed to grow to $70 \%$ fusion degree. For cell collection, cells were washed with phosphate-buffered saline (PBS) 2-3 times, digested with trypsin without EDTA, and gently blown on to prevent cell damage. Cells were collected by centrifugation at $1,000 \mathrm{rpm}$ for $3 \mathrm{~min}$. For washing, the cells were resuspended with $400 \mu \mathrm{L}$ of binding buffer. AV and PI dyes were added at $4 \mu \mathrm{L}$ each, and mixtures were incubated respectively for $15 \mathrm{~min}$ in the dark. BD FACSCalibur (BD, Bioscsciences, San Jose, CA, USA) flow cytometry was used to detect the staining.

\section{Statistical analysis}

All statistical analyses were carried out using IBM SPSS Statistics 26 (IBM, Armonk, NY, USA). Differences in baseline data and clinicopathological factors between the two groups with high and low leptin expression were compared, with the count data being analyzed by chi-square test and Fisher's exact test, and measurement data being analyzed by two independent samples $t$-tests. Kaplan-Meier survival analysis was used to plot survival curves, log-rank test was used to test the differences between the curves, single-factor analysis with Cox proportional risk regression model was used to calculate the risk ratio (HR) and 95\% confidence interval, and multivariate analysis of Cox proportional risk regression model was used to correct HR and $95 \%$ confidence intervals (CI) of statistically significant 
variables in univariate analysis.

\section{Results}

\section{The expression of LEP analyzed from the Oncomine} database

We retrieved sequence datasets of 389 genes from the Oncomine database: 42 datasets showed significant differences of $L E P$ gene expression in different tumor types compared with normal control tissue (cells), 38 datasets showed lower expression in breast cancer, colon cancer, pancreatic cancer, and sarcoma. There were datasets concerning the high expression level of $L E P$ in esophageal cancer, lymphoma, kidney cancer, or pancreatic cancer, but there was no report about the expression level of LEP in lung cancer (Figure 1A).

We retrieved the results for the gene rank of $L E P$ genes, specifically the top five gene expression difference data between lung cancer tissue and normal lung tissue. The expression of LEP in lung adenocarcinoma $(\mathrm{n}=527)$ was higher than in normal lung tissue $(\mathrm{n}=1,002)$. In four of the five datasets (Figure 1B,C,D,E,F), $\log 2$ median expression differences in the ratio of mRNA ranged from 1.5 to 2.4. The remaining dataset showed no difference in expression between tumor and normal tissue.

\section{The expression of LEP in different pathological subtypes of lung adenocarcinoma detected in sample 1}

Tumor tissue samples and normal lung tissue samples of six patients with different pathological subtypes of lung adenocarcinoma were collected to observe the differential expression of leptin, and leptin overexpression was observed in tumor tissues (Figure 1G).

We detected leptin expression in six pairs of different pathological subtypes of lung carcinoma. Results showed that leptin was overexpressed in five of six pairs of cancer tissues, with the non-overexpressed sample being a lepidic predominant adenocarcinoma (LPA) subtype (Figure 2).

\section{LEP expression levels and detailed clinical data analyzed in sample 2}

Tumor tissue of 60 patients, 29 males and 31 females with an average age of $62.4 \pm 8.6$ years and a median age of 64 with stage II-III lung adenocarcinoma were embedded in paraffin. We divided tumor tissue specimens into a high expression group (37 cases) and a low expression group (23 cases) according to the leptin expression level by leptin IHC staining, using consistent assessment methods.

Analysis of the relationship between leptin expression levels and various clinicopathological factors (Table 1) showed that leptin expression levels were not associated with baseline data such as gender, age, or smoking history. Of T stage, $\mathrm{N}$ stage, and clinical pathological stage, leptin expression levels related to $\mathrm{T}$ stage $(\mathrm{P}=0.041)$ and clinical pathological stage $(\mathrm{P}=0.032)$. The higher the leptin expression level, the more advanced the stages, which suggests that the expression of leptin in lung adenocarcinoma itself may promote the proliferation of tumor cells. Within a 5-year follow-up period, patients with high expression of leptin had a lower 5-year survival rate than those with low leptin expression $(\mathrm{P}=0.033)$. KaplanMeier survival analysis showed a higher risk of long-term survival $(\mathrm{P}=0.013)$ over a 5 -year follow-up period (Figure 3). Meanwhile, $\mathrm{T}$ stage $(\mathrm{P}=0.003)$ and $\mathrm{N}$ stage $(\mathrm{P}=0.000)$ could also significantly affect the long-term survival risk of patients. The indications of increased survival risks in older patients compared to lower age groups, but this was a statistically non-significant difference $(\mathrm{P}=0.174)$, which could be ruled out as a sampling error. Correction by Cox proportional hazards regression model of multiple factors (Table 2) indicated that $\mathrm{T}$ stage and $\mathrm{N}$ stage had significant effect on long-term survival risk, but the expression of leptin level had no statistical significance as an independent predictor of long-term prognosis.

\section{Gene heatmap to express relationships between the genes in cell signaling patbways with the LEP gene}

"limma" package of the $\mathrm{R}$ programming language was used to calculate the differential expression of genes of 524 lung adenocarcinoma tissue samples. The "clusterProfiler" package from the $\mathrm{R}$ program was used for GSEA and visualization of the co-expression of genes with the $L E P$ gene, with a $\mathrm{P}$ value $<0.05$ being considered statistically significant.

It was shown that the $P I 3 K / A K T / m T O R$ signal pathway were positively enriched in leptin-overexpressed NSCLC cases, while the P53 signal pathway were negatively enriched in leptin-overexpressed NSCLC cases. Gene enrichment curves and gene set zero distribution curves were displayed in Figure 4.

With the increasing expression level of $L E P$ gene in lung adenocarcinoma, a large number of genes belonging to 


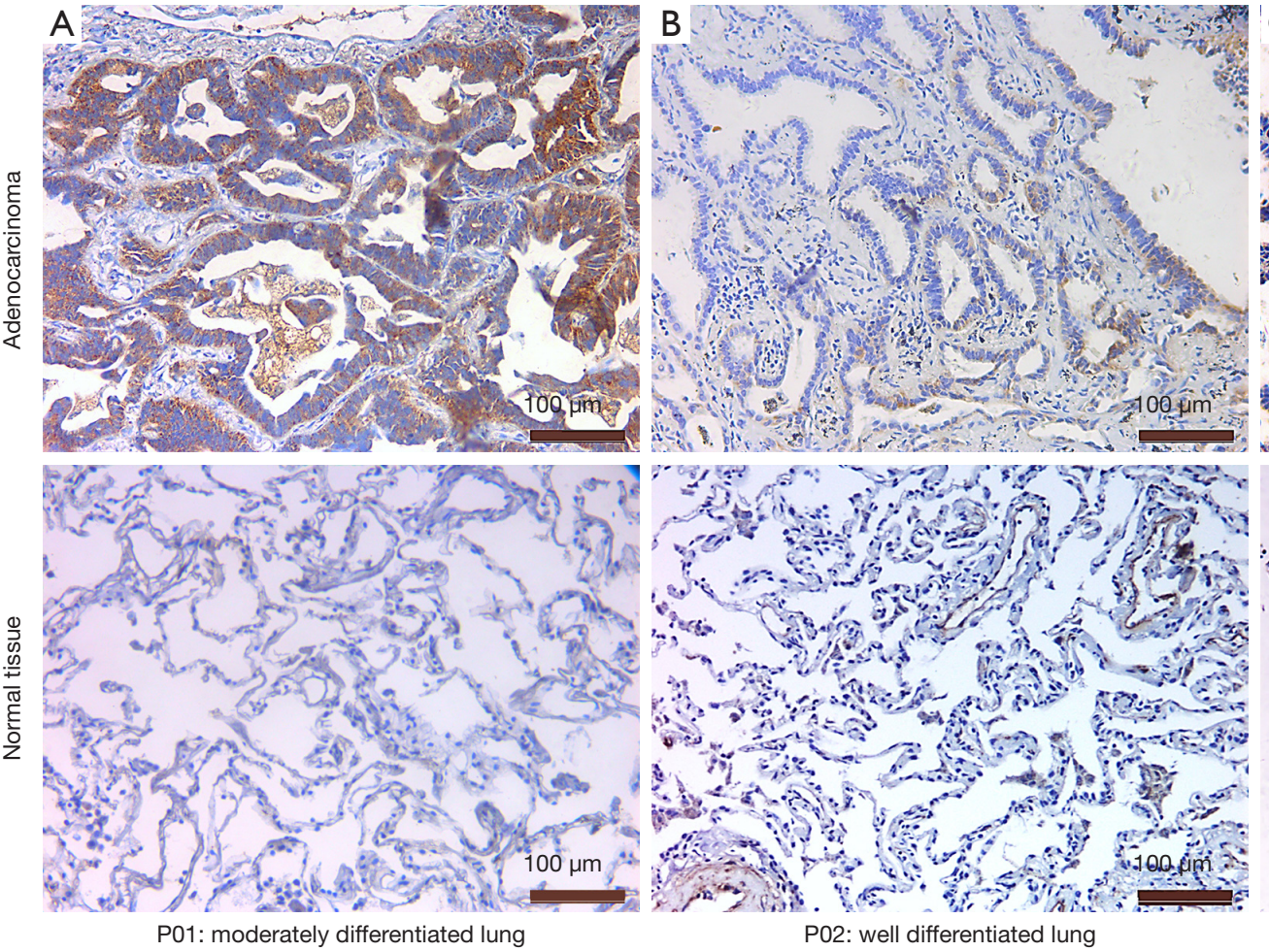
P01: moderately differentiated lung
addencarcinoma with acinar
predominant growth

\section{P02: well lifferentiated lung
adenocarcinoma with lepidic}

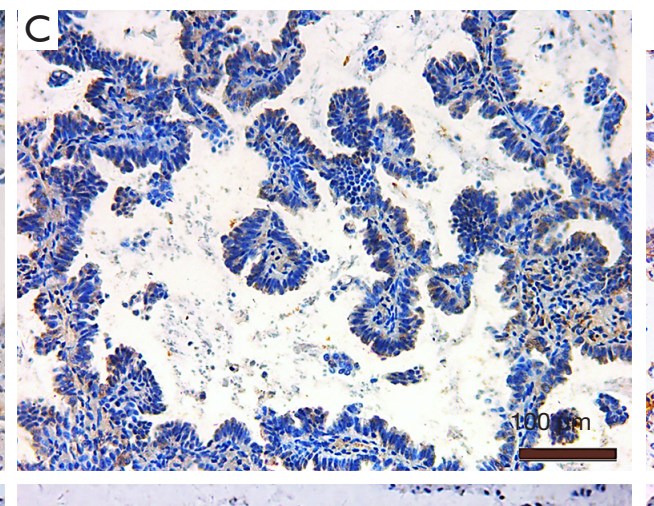

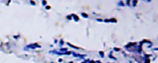

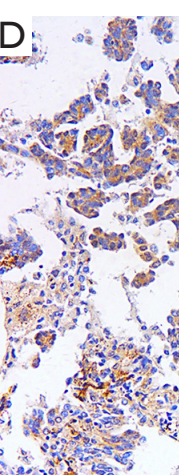

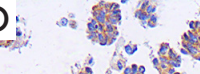
$x^{2}+12$ 2. How 1.

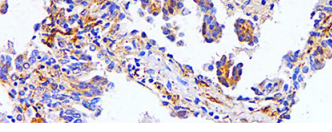
ooging
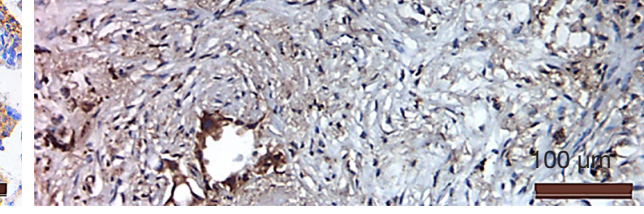

\section{$4013+2 x$ \\ Th $=0,4$ \\ 3) $3(1,2)$

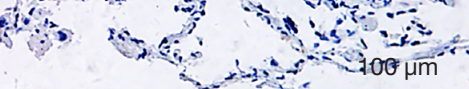

Po3: highly difierentiated ling
adenocacarioman with

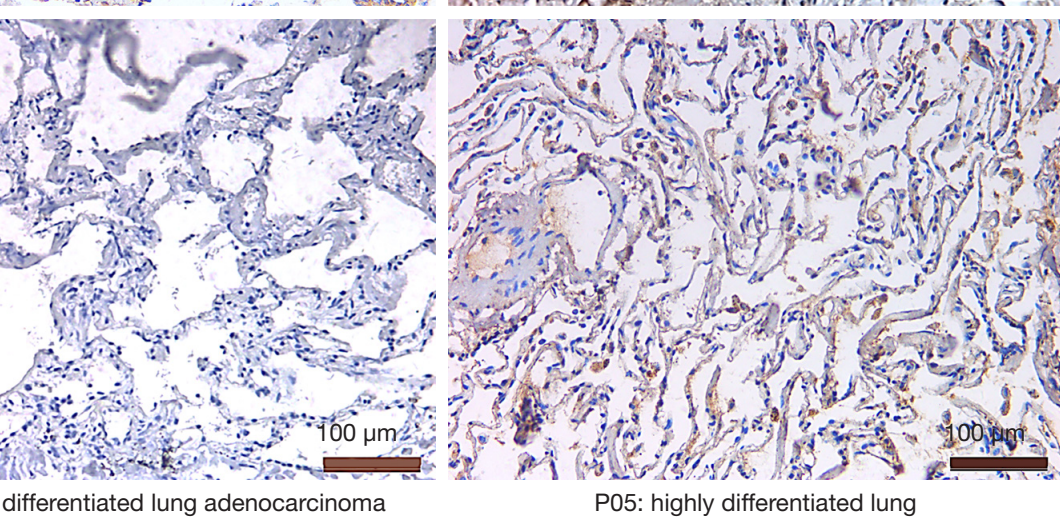

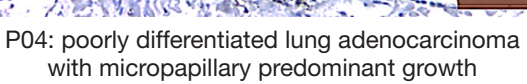

(E)

(t)

adenocarcinoma with solid pred udominant

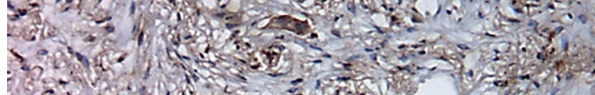

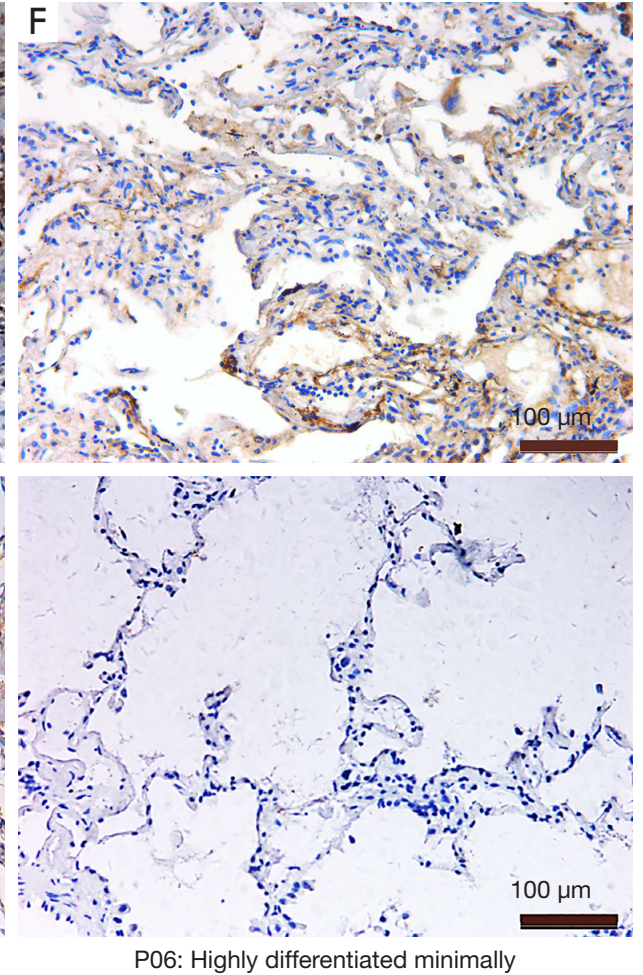

Po: : Highly differentiated minimally
invasive adenocarcinoma (MAA)

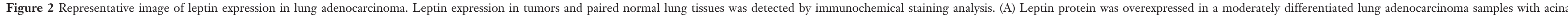

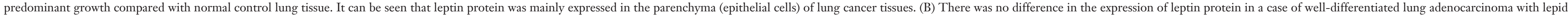

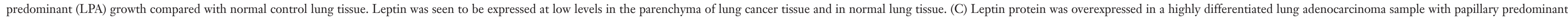

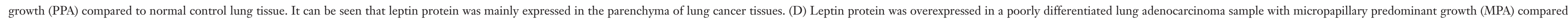

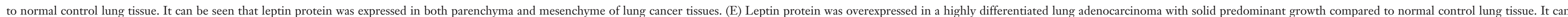

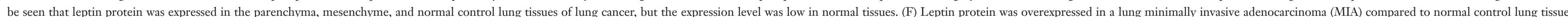

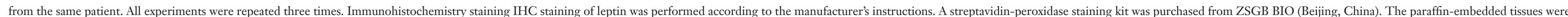

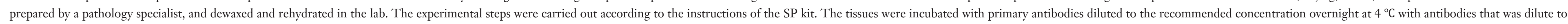
the recommended concentration. Then $3,3^{\prime}$-diaminobenzidine (DAB) staining was performed, and the results were observed under a microscope. 
Table 1 Relationship between Leptin expression level and various clinicopathological factors

\begin{tabular}{|c|c|c|c|c|c|}
\hline Variable & Total & Low leptin & High leptin & $\chi^{2}$ & $\mathrm{P}$ \\
\hline Number of patients & 60 & 23 & 37 & - & - \\
\hline \multicolumn{6}{|l|}{ Gender } \\
\hline Male & 29 & 9 & 20 & 1.265 & 0.298 \\
\hline Female & 31 & 14 & 17 & & \\
\hline Age & & & & & 0.109 \\
\hline$<64$ & 33 & 12 & 21 & 0.120 & 0.793 \\
\hline$\geq 64$ & 27 & 11 & 16 & & \\
\hline \multicolumn{6}{|l|}{ Smoking history } \\
\hline None & 30 & 14 & 16 & 1.763 & 0.288 \\
\hline Yes & 30 & 9 & 21 & & \\
\hline \multicolumn{6}{|l|}{$\mathrm{T}$} \\
\hline $\mathrm{T} 1$ & 14 & 9 & 5 & 6.620 & 0.041 \\
\hline $\mathrm{T} 2$ & 30 & 11 & 19 & & \\
\hline $\mathrm{T} 3 / \mathrm{T} 4$ & 16 & 3 & 13 & & \\
\hline \multicolumn{6}{|l|}{$N$} \\
\hline No & 7 & 2 & 5 & 3.774 & 0.335 \\
\hline N1 & 30 & 15 & 15 & & \\
\hline N2 & 17 & 5 & 12 & & \\
\hline N3 & 6 & 1 & 5 & & \\
\hline \multicolumn{6}{|l|}{ Pathological staging } \\
\hline II & 33 & 17 & 16 & 5.390 & 0.032 \\
\hline III & 27 & 6 & 21 & & \\
\hline \multicolumn{6}{|l|}{ Survival rates } \\
\hline Survive & 30 & 16 & 14 & 5.711 & 0.033 \\
\hline
\end{tabular}

Italic $\mathrm{P}$ values indicate significant intergroup differences $(\leq 0.05)$.

the $P I 3 K / A K T / m T O R$ signaling pathway were significantly enriched (Figure 4A). Most of these genes were positively enriched when the LEP gene was highly expressed, and a small number were underexpressed when LEP gene expression was low. The significance of gene enrichment $(\mathrm{P}=0.0237)$ and the false-positive rate $(\mathrm{FDR}=0.182)$ (Figure $4 B$ ) indicated that there was a positive regulatory relationship between the $P I 3 K / A K T / m T O R$ signaling pathway and the $L E P$ gene.

Increased $L E P$ gene expression in lung adenocarcinoma was also correlated with a significant enrichment of a large number of genes belonging to the $p 53$ signaling pathway (Figure 4C); most of these genes were negatively enriched when the LEP gene was highly expressed, and a small number were positively enriched when the LEP gene was underexpressed. The significance of gene enrichment $(\mathrm{P}=0.000)$ and FDR (0.054) (Figure 4D) indicated that there was a strong negative regulatory relationship between $p 53$ signaling pathway and the $L E P$ gene.

The heat map was drawn based on the changes in gene expression in the PI $3 K / A K T / m T O R$ and $p 53$ signaling pathways with $L E P$ gene expression levels in lung adenocarcinoma (Figure 5). The genes in the two signaling pathways are consistent with LEP gene expression in general.

\section{LEP gene expression level correlation with signaling pathway gene expression levels acquired in the KEGG database}

We visualized the levels of the correlation of lung adenocarcinoma LEP gene expression with signaling pathway gene expression in 524 case samples acquired in the KEGG database, using the "pathview" package of $\mathrm{R}$ language. This provided visual evidence to explore the potential molecular mechanism of the endogenous $L E P$ gene in lung adenocarcinoma cells that affects the proliferation of lung adenocarcinoma.

Among the genes belonging to the PI3K/AKT/mTOR signaling pathway, the expression levels of 36 genes were significantly correlated with $L E P$ genes, while in those genes belonging to the $p 53$ signaling pathway, the expression levels of 82 genes were significantly correlated with the $L E P$ gene. Affiliations of genes and signaling pathways in the list were acquired from the KEGG database (https://www. genome.jp/kegg/). Human gene information was obtained from the China National Gene Bank Data Platform (https:// db.cngb.org).

The correlation between the expression level of signaling molecules in PI3K/AKT/mTOR (Figure 6) and p53 (Figure 7) signaling pathways and $L E P$ gene expression levels are shown by KEGG cell signaling maps. Red indicates a positive correlation, and green indicates a negative correlation. It can be seen from the figure that the $L E P$ gene is closely related to several important molecules in PI3K/AKT/mTOR and p53 signaling pathways, including PI3K, CCND1 (cyclin D1), $L C 3, M E K, E R K, C D K 2, N F-\kappa B$, etc. Furthermore, the $P I 3 K / A K T / m T O R$ signaling pathway and the $p 53$ signaling pathway are also closely related to the signaling molecule, $M D M 2$; the function of $p 53$ is negatively regulated by the 

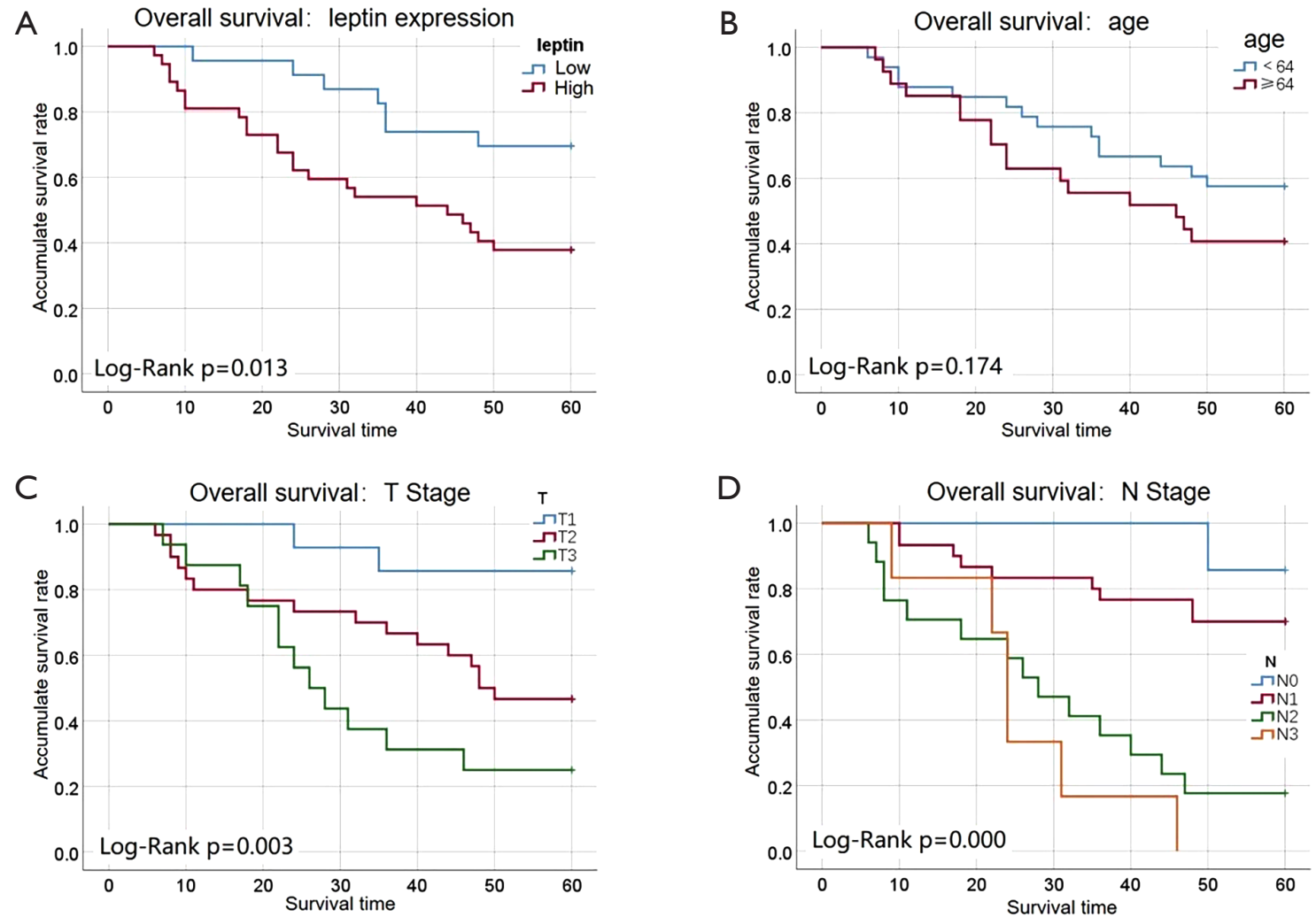

Figure 3 The relationship between leptin expression level and long-term prognosis in patients with lung adenocarcinoma. (A) Leptin levels significantly affect a patient's overall survival risk $(\mathrm{P}=0.013)$; $(\mathrm{B})$ age affects a patient's overall survival risk $(\mathrm{P}=0.174) ;(\mathrm{C}) \mathrm{T}$ stage significantly affects the overall survival risk of the patient $(\mathrm{P}=0.003)$; (D) $\mathrm{N}$ stage significantly affects the overall survival risk of the patient $(\mathrm{P}=0.000)$.

Table 2 COX proportional hazard regression model in 60 patients with lung adenocarcinoma

\begin{tabular}{|c|c|c|c|c|}
\hline \multirow{2}{*}{ Variable } & \multirow{2}{*}{ HR } & \multicolumn{2}{|c|}{$95 \% \mathrm{Cl}$} & \multirow{2}{*}{$\mathrm{P}$} \\
\hline & & Lower & Upper & \\
\hline Gender (male) & 1.399 & 0.682 & 2.869 & 0.360 \\
\hline Smoking history (yes) & 1.281 & 1.091 & 1.504 & 0.003 \\
\hline \multicolumn{5}{|l|}{ Leptin } \\
\hline High & 2.778 & 1.190 & 6.486 & 0.018 \\
\hline \multicolumn{5}{|l|}{$\mathrm{T}$} \\
\hline $\mathrm{T} 1$ & 1.000 & & & \\
\hline $\mathrm{T} 2$ & 4.784 & 1.099 & 20.818 & 0.037 \\
\hline T3 & 9.058 & 2.012 & 40.785 & 0.004 \\
\hline $\mathrm{N} 1$ & 2.533 & 0.321 & 20.003 & 0.378 \\
\hline N2 & 12.526 & 1.629 & 96.304 & 0.015 \\
\hline N3 & 19.184 & 2.231 & 164.971 & 0.007 \\
\hline
\end{tabular}

Italic $\mathrm{P}$ values indicate significant intergroup differences $(\leq 0.05)$. $\mathrm{HR}$, hazard ratio; $\mathrm{Cl}$, confidence interval. 
A

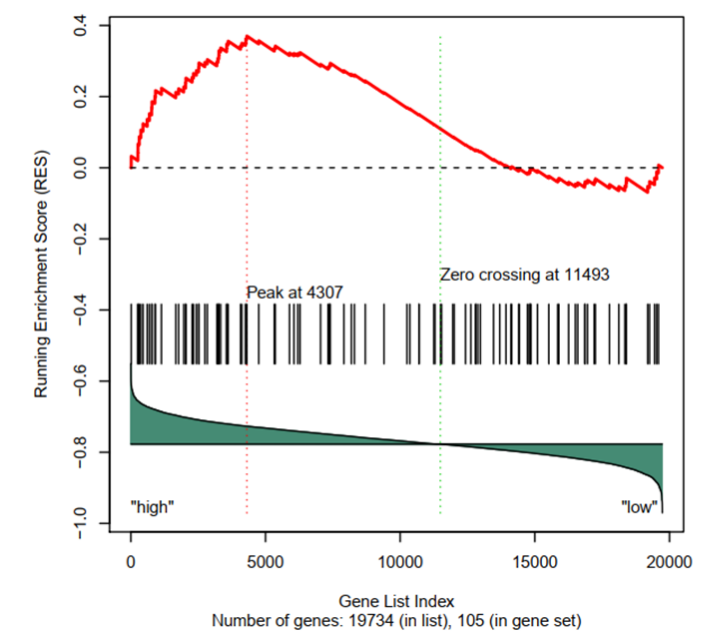

C

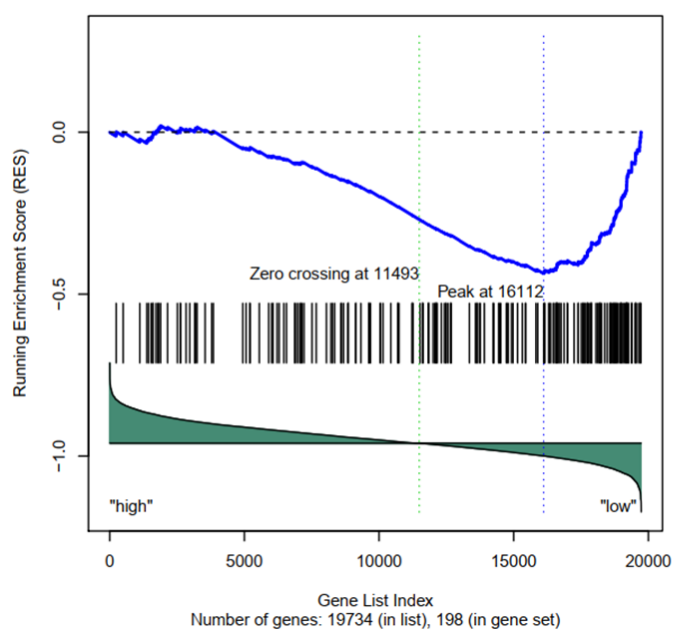

B

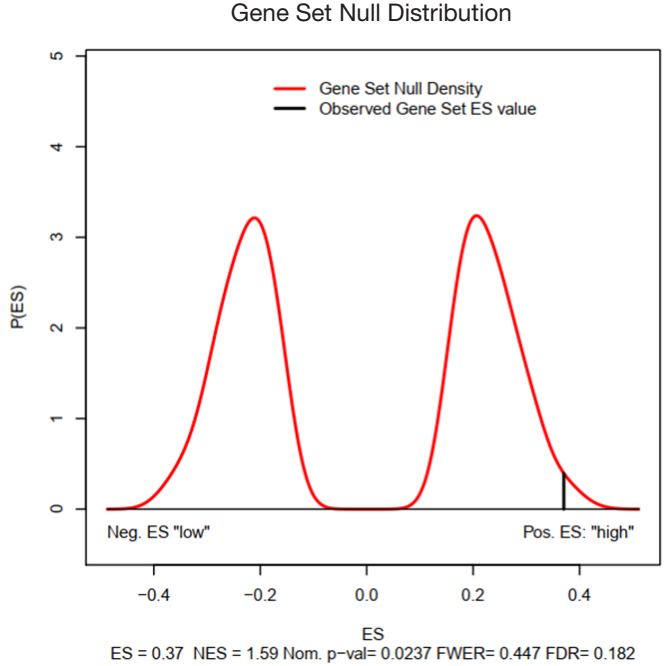

D

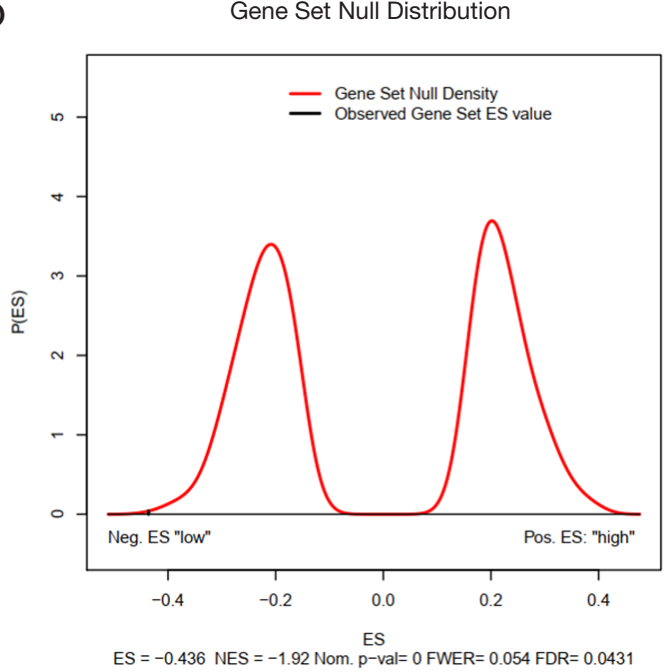

Figure 4 Genes of PI3K/AKT/mTOR signaling pathway and $p 53$ signaling pathway were enriched with increased LEP gene expression in lung adenocarcinoma. (A) With the expression of LEP gene in lung adenocarcinoma, significant enrichment occurred in the PI3K/ AKT/mTOR signaling pathway, which was mainly positively enriched when the LEP gene was highly expressed, and slightly negatively enriched when the LEP gene was underexpressed. (B) The PI3K/AKT/mTOR gene set null distribution curve (significance of the gene enrichment $\mathrm{P}=0.0237$, FDR $=0.182$ ). (C) Gene enrichment curve of $\mathrm{p} 53$ signaling pathway. With the level of LEP gene expression in lung adenocarcinoma increased, significant enrichment occurred in genes belonging to the p53 signaling pathway; these genes were negatively enriched when the LEP gene was highly expressed, and a small number were positively enriched when LEP gene expression was low. (D) p53 gene set null distribution curve (significance of the gene enrichment $\mathrm{P}=0.000, \mathrm{FDR}=0.0431$ ). ES, enrichment score. NES, normalized enrichment score. FWER, family wise error rate. FDR, false discovery rate.

PI3K-AKT-MDM2-p53 signal axis (Figures 6,7). Therefore, it can be inferred that the LEP secreted by the lung adenocarcinoma cells promotes the proliferation ability of lung adenocarcinoma cells by regulating the activity of their own PI3K/AKT/mTOR and $p 53$ signaling pathways. These signaling factors strictly regulate a series of biological functions related to tumor proliferation.

\section{LEP gene expression levels in four NSCLC lines}

Human NSCLC cell lines, A549, H1299, H460, and $\mathrm{H} 322$, were collected and cultured in vitro, with human 
A

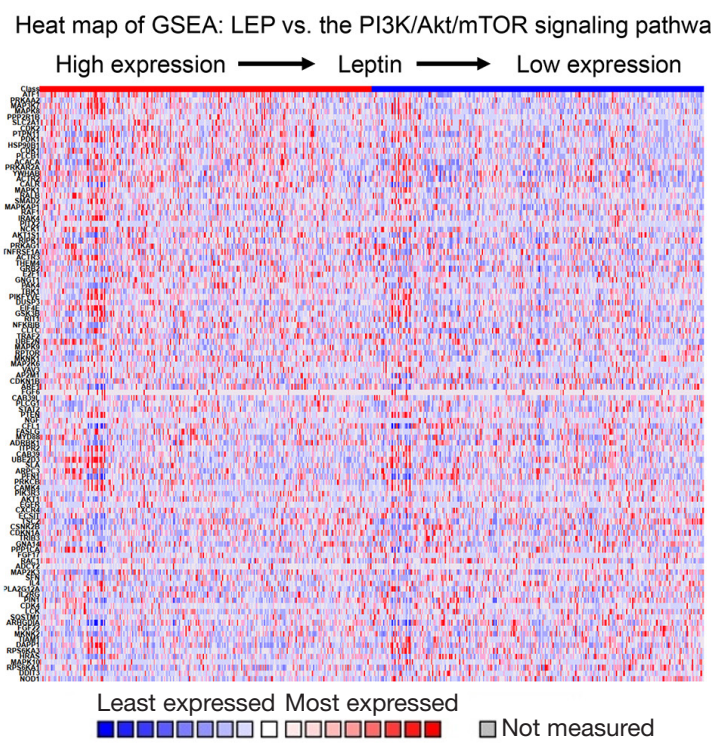

B

Heat map of GSEA: LEP vs. the P53 signaling pathway

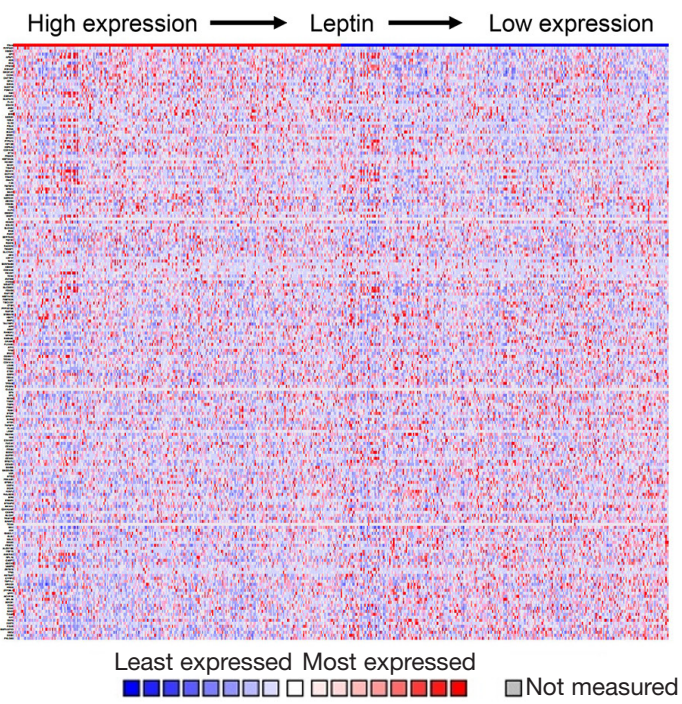

Figure 5 Heat map of PI $3 K / A K T / m T O R$ signaling pathway and $p 53$ signaling pathway enriched with $L E P$ gene in lung adenocarcinoma. (A) PI3K/AKT/mTOR signaling pathway heat map; (B) $p 53$ signaling pathway heat map.

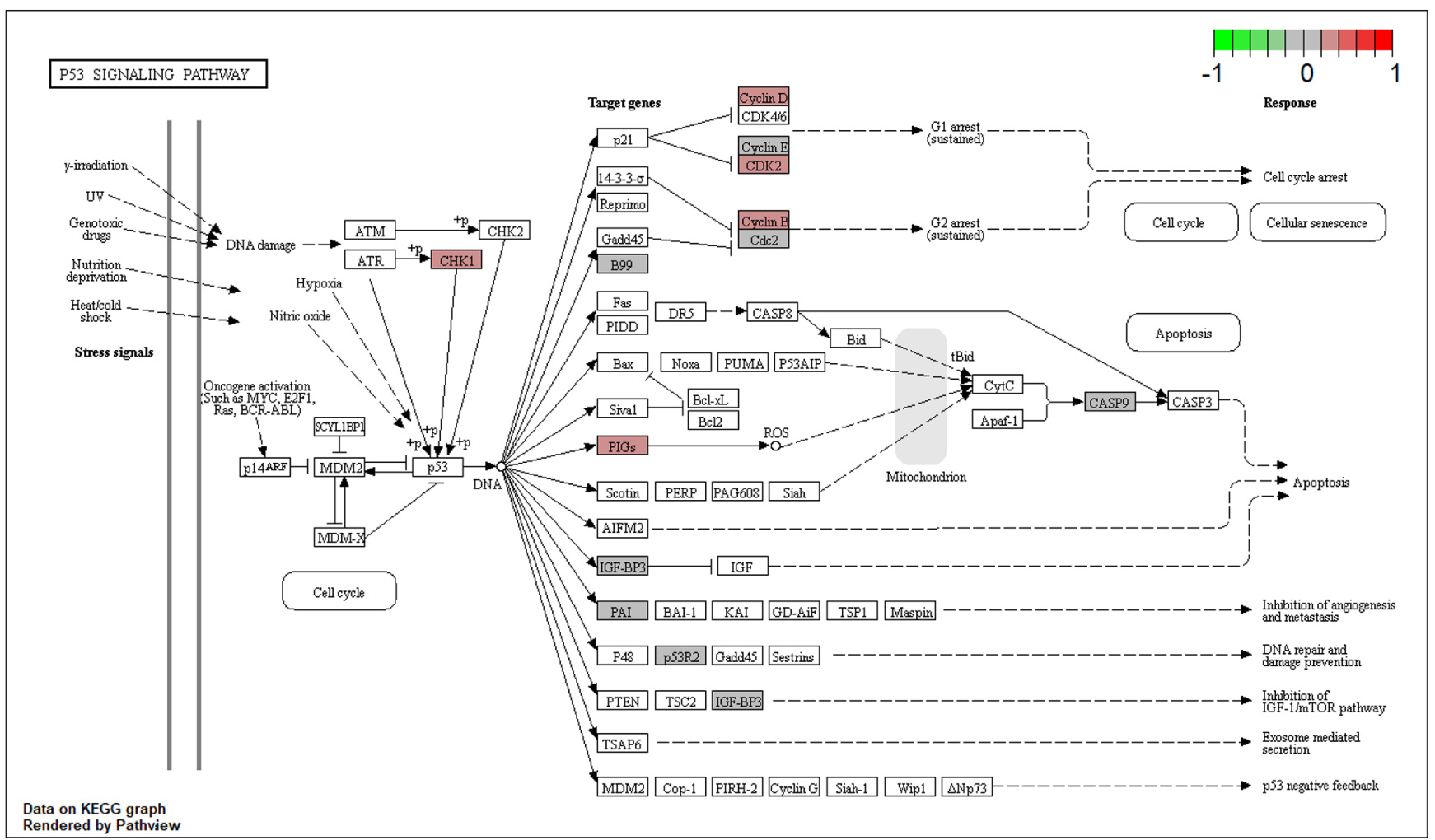

Figure 6 Map of $P I 3 K / A K T / m T O R$ signaling pathway regulated by the $L E P$ gene drawn through the KEGG database. 


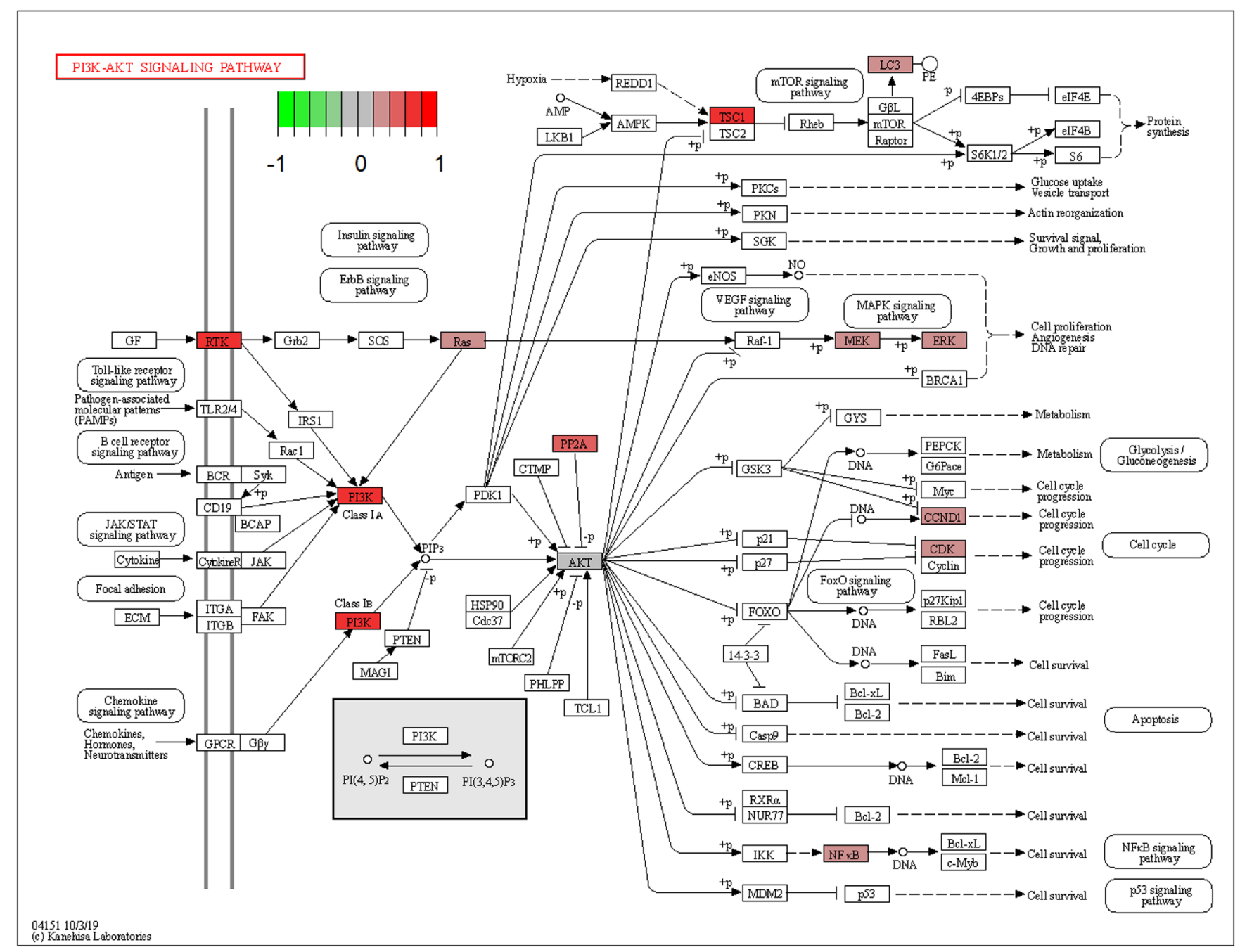

Figure 7 Map of p53 signaling pathway regulated by LEP gene drawn through the KEGG database.

embryonic lung fibroblasts (HLF) and HBE cells used as their control group. Total RNA was collected and extracted from the above six cell lines, and the first cDNA strand was synthesized by reverse transcription. The background expression level of the LEP gene mRNA in the above six cell lines was detected by PCR. Semi-quantitative analysis showed that the expression levels of leptin in the four NSCLC cell lines were higher than those in the HLF and HBE cells. H1299 had the highest expression level of leptin mRNA, the expression level of leptin was slightly lower in H322, and the expression levels of A549 and H460 were the lowest (Figure 8A). We further analyzed the total protein expression of A549, H1299, H460, H322, and the control cell line HLF by western blotting, the results were of which similar to those of PCR. The expression of leptin in NSCLC cells was higher or higher than that of the normal control cells. Among these H1299 had the highest expression level of leptin, A549 had a lower expression of leptin, and H460 had the lowest expression (Figure 8B).

\section{Clonal formation assays}

To verify the role of leptin in lung adenocarcinoma cells, we knocked down $L E P$ gene and leptin protein expression levels in H1299 by transient transfection with four shRNA fragments (Figure 8C). It can be seen that of the four shRNA fragments, shRNA1 (sh1) and shRNA2 (sh2) manifested a significant effect on silencing the LEP gene. Meanwhile, leptin expression level in A549 cells was up-regulated by the ORF fragments of LEP gene, as shown in Figure 8C. 
A
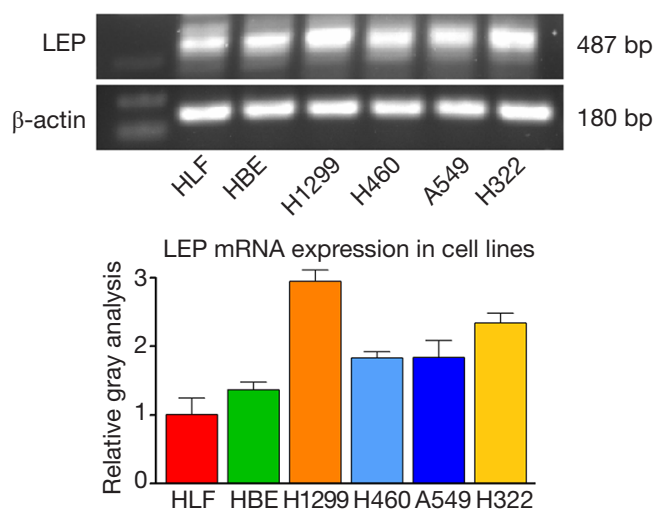

B
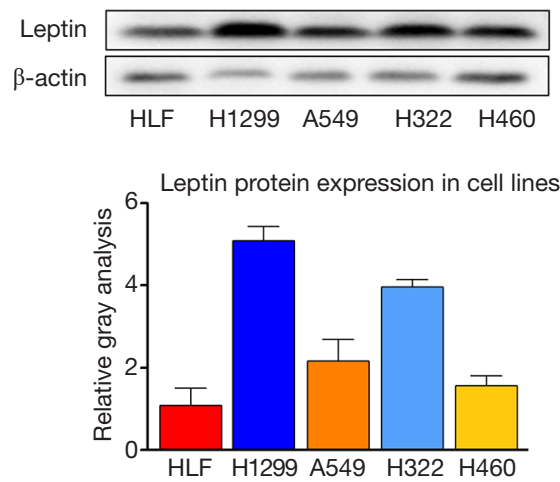

C
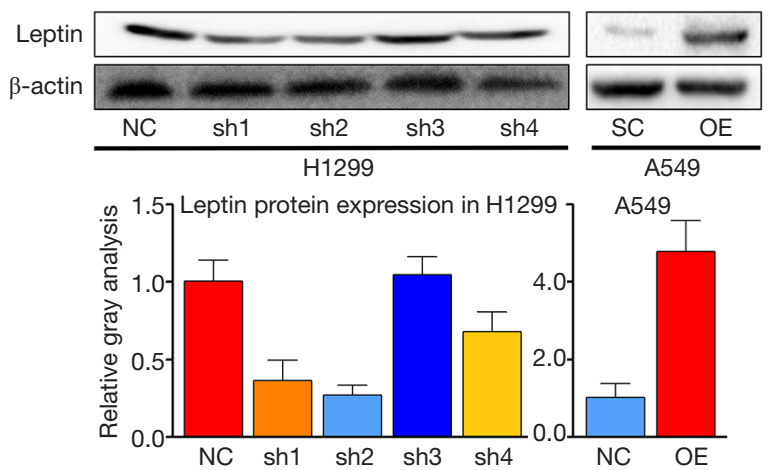

Figure 8 The detection and intervention of LEP expression in the lung cancer cell system. (A) RT-PCR detected LEP expression in the mRNA of four types of human lung adenocarcinoma and two control cell lines; (B) Western blot shows the expression of leptin protein in four types of human lung adenocarcinoma and HLF cells; (C) the intervention effect of shRNA instant transfection on the expression level of leptin in h1299 cells. All the experiments were repeated three times.

Clonal formation assays showed the expression of endogenous leptin in H1299-sh was silenced compared to the H1299-NC cells transferred to the empty control plasmid. Its ability to form clones was weakened, the expression level of endogenous leptin was upregulated in a549-LEP-OE cells, and its clonal formation ability was significantly enhanced compared with a549- NC cells (Figure $9 A$ ). When $50 \mathrm{ng} / \mathrm{mL}$ of recombinant leptin was added to a549- NC cells, the effect was similar to that of the upregulation of endogenous leptin expression. These results showed that endogenous leptin had the same effect on promoting cell proliferation as exogenous leptin.

\section{Effects of LEP gene on cell cycle and apoptosis}

The flow cell cycle analysis of PI staining showed that compared with H1299-nc cells, H1299-lepsh cells had cycle arrest, and the proportion of cells in G1 phase increased, while that in the $\mathrm{S}$ phase decreased. Correspondingly, A549-LEP-
OE cells promoted cell cycle compared with a549- NC cells, with the proportion of cells decreased in the G1 phase and increased in the $\mathrm{S}$ phase (Figure 9B). On the basis of inference, leptin may play an important role in pushing cell cycles past G1/S checkpoints, which is in accord with our previous results. The expression level of the LEP gene in lung adenocarcinoma is consistent with the results of cell cycle G1/S checkpoint regulatory proteins such as CDK2, cyclin D1, etc. Meanwhile, AV/PI double-staining flow cytometry apoptotic cell detection showed that the apoptosis rate of H1299-sh cells was higher than that of H1299-NC cells, while the overexpression of LEP gene also significantly decreased the apoptosis rate of A549 cells (Figure 9C). This suggests that leptin plays an antiapoptotic role in lung adenocarcinoma cells.

\section{The role of LEP in regulating PI3K/AKT/mTOR and $p 53$} signaling patbways

Compared with H1299-NC cells, H1299-LEPsh the 

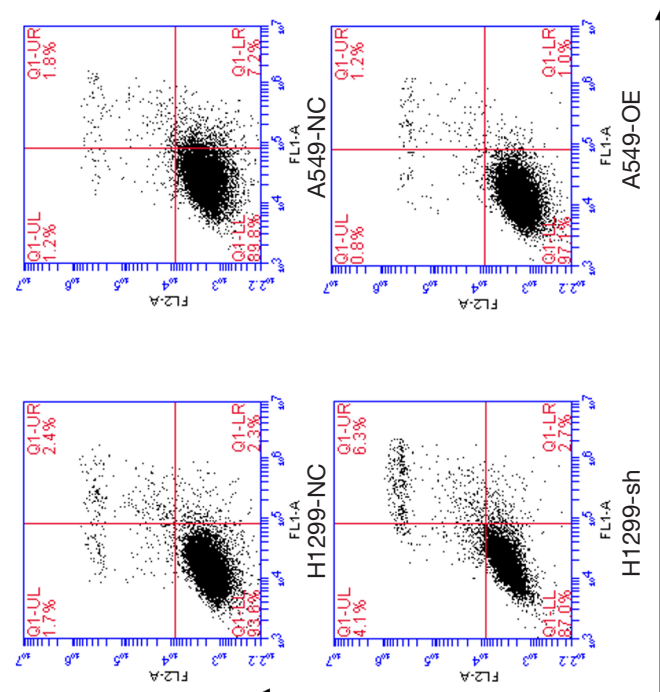

U

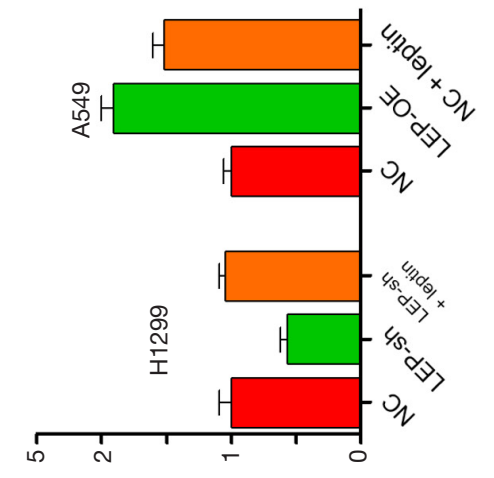

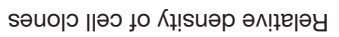

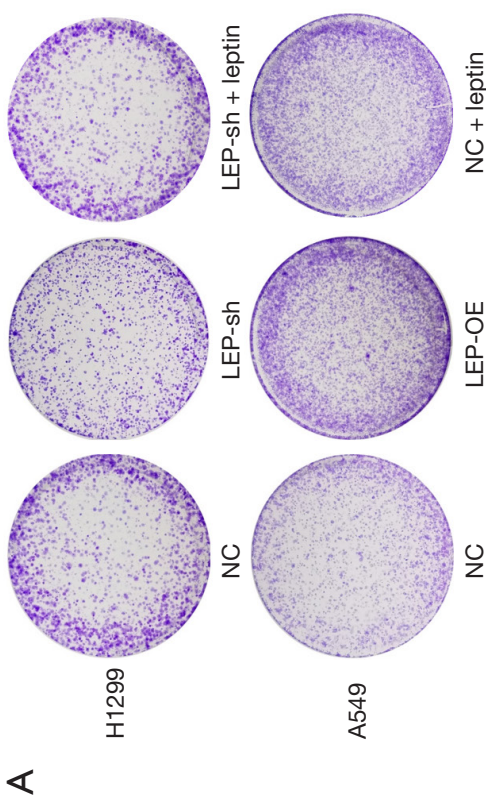

$\infty$

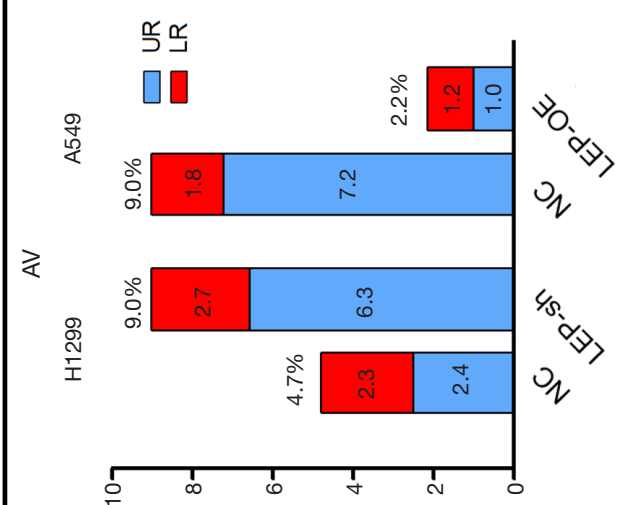

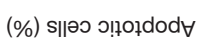

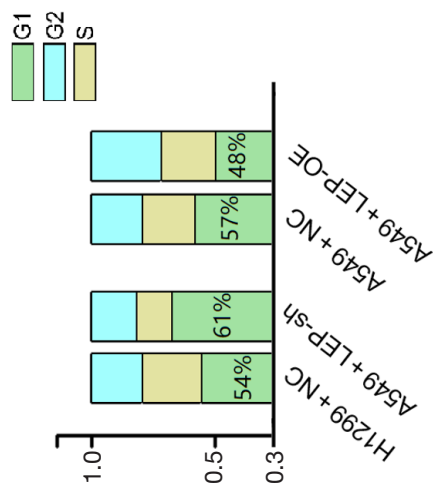

(\%) о!̣eג sәseud әрКК ॥ә弓

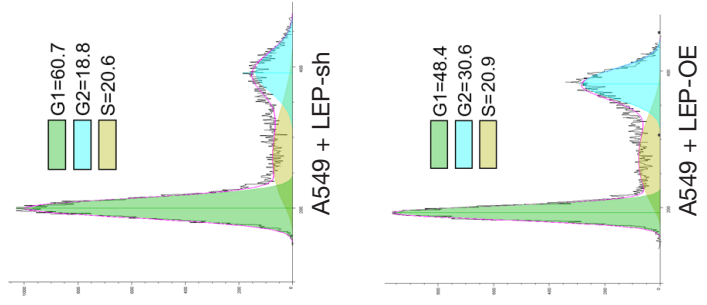

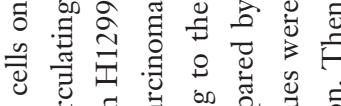
文.

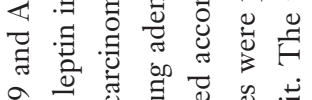

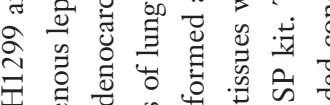

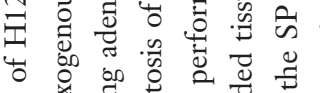

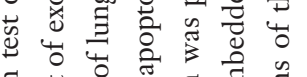

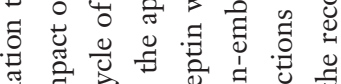

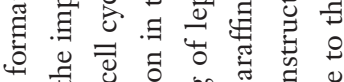
ษ 은 吾 E है

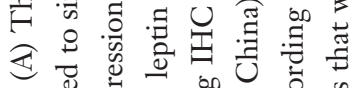

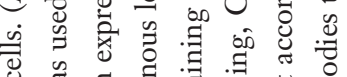

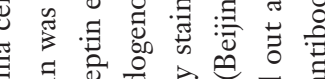

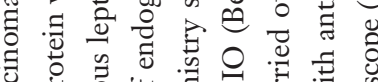
苞

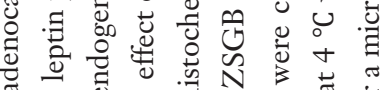
光

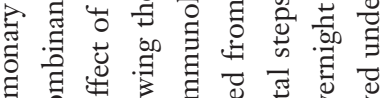

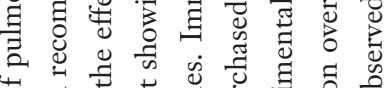

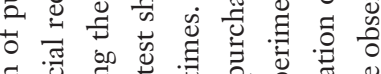

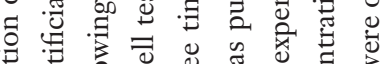

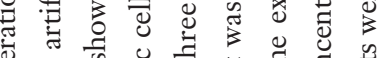

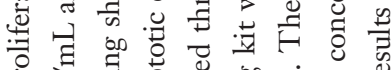
के 记

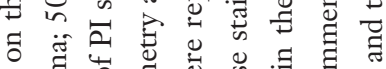

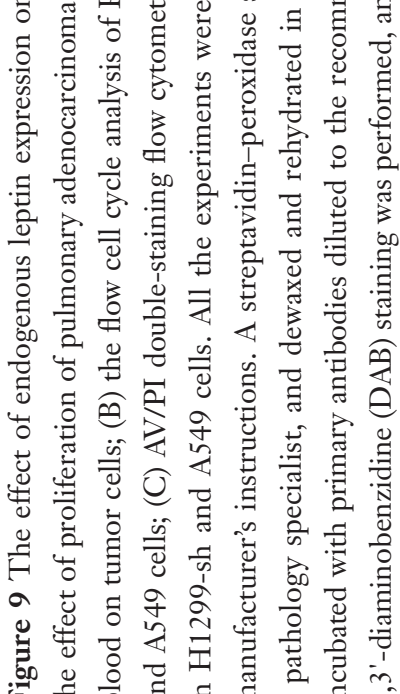

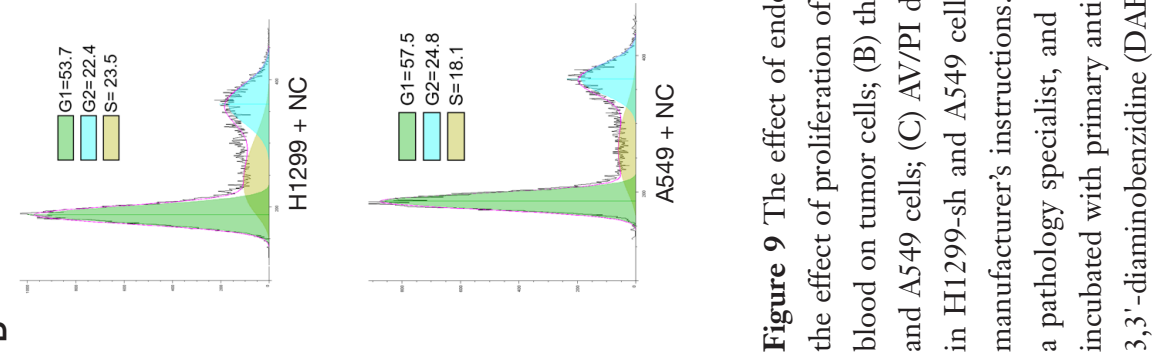


A

C
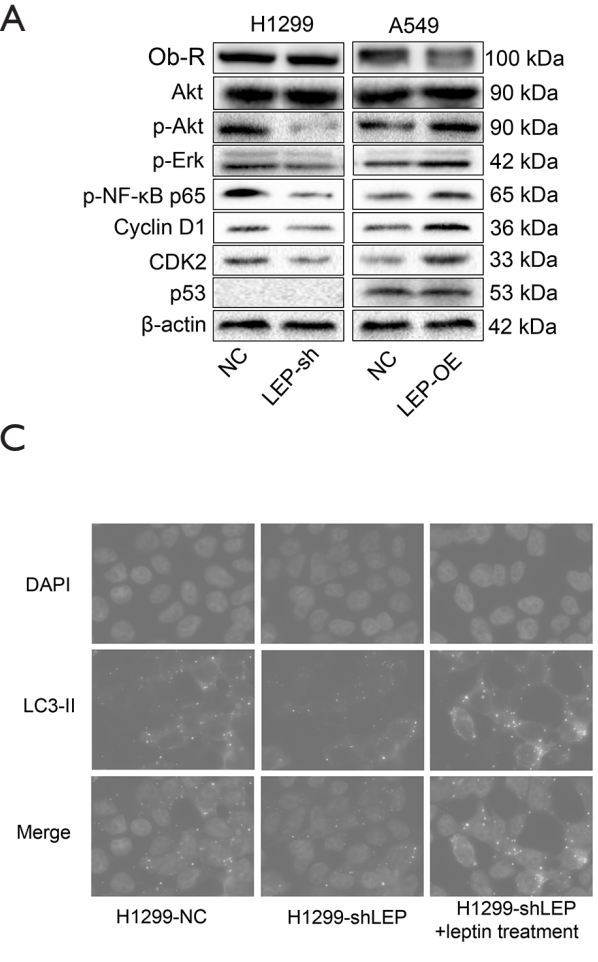

B
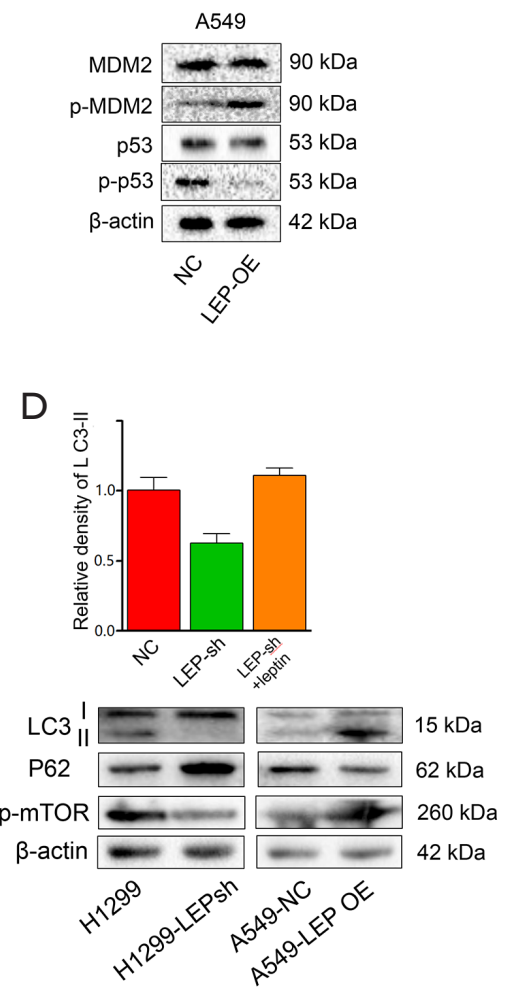

Figure 10 Molecular mechanisms of endogenous leptin expression effect on the proliferative ability of lung adenocarcinoma cells. (A) Effect of endogenous leptin expression on key signaling molecules of PI3K/AKT pathway and its downstream signaling pathway in H1299 and A549 cells detected by western blotting; (B) effect of endogenous leptin expression on the p53 signaling pathway in A549 cells by western blotting; (C) endogenous leptin expression level on the expression level of autophagy-related protein LC3-II in H1299 cell lines detected by protein immunofluorescence. (D) Effect of endogenous leptin expression on key signaling molecules of the mTOR pathway and its downstream signalings in H1299 and A549 cells detected by western blotting. All the experiments were repeated three times. Scale bar: $50 \mu \mathrm{m}$.

expression level of endogenous leptin receptor (Ob-R) did not change, and the expression level of AKT was not significantly changed, but its phosphorylation level was significantly decreased. The phosphorylation levels of ERK and NF-kB p65 also decreased. The expression levels of cyclin D1 and CDK2 were downregulated (Figure 10A). Accordingly, compared with A549-NC, in A549-LEP-OE cells, the above molecules exhibited the opposite changes. H1299 cells were absent of the $p 53$ gene, and the expression of $p 53$ protein was not detected in either H1299-LEPsh or H1299-NC cells.

Western blotting further showed that, compared with A549-NC cells, the A549-LEP-OE cell phosphorylation of the MDM2 protein increased, while the phosphorylation level of p53 protein decreased (Figure 10B). This indicated that the activity of $\mathrm{p} 53$ pathway was negatively correlated with the expression level of leptin.
At the same time, images of protein immunofluorescence showed that H1299 and LC3-II protein expression levels were also downregulated after leptin knockdown (Figure 10C). After $50 \mathrm{ng} / \mathrm{mL}$ of artificially recombinant leptin was added to the medium of leptin knockout H1299 cells, the expression level of LC3-II was once again upregulated. The results of western blotting analysis showed that the mTOR phosphorylation levels and LC3-II expression were downregulated while the expression of leptin was knocked down in H1299 cells, and up-regulated while the expression of leptin was up-regulated in A549, and the P62 expression manifested a reversed tendency in either groups (Figure 10D).

\section{Discussion}

A large number of studies have suggested that the cancer- 
promoting role of leptin in different cancers, some of these studies have also suggested that leptin has potential as an anticancer drug target. In the current study, we explored the phenomenon and mechanism by which autocrined leptin promotes the proliferation of NSCLC. We first detected the expression levels of leptin in six lung adenocarcinoma specimens and their paired normal lung tissues. It was found that leptin was overexpressed in the majority of these six tumor tissues compared with each paired normal tissue. It was also found that with the increase of the malignancy of the cancer subtypes, the expression of leptin protein increased gradually compared with normal tissues. In the adenocarcinoma tissues with a higher degree of malignancy, such as lung adenocarcinoma with micropapillary and solid predominant growth, LEP expression was increased not only in the tumor itself, but also in the tumor stroma.

Furthermore, we explored the relationship between leptin expression and lung-term prognosis in lung adenocarcinoma patients. It was shown that the leptin expression level could serve as an auxiliary prognostic factor in addition to $\mathrm{T} 、 \mathrm{~N}$ stage and age in 60 patients. These results suggested that leptin may play an important role in the development of lung adenocarcinoma.

In our study, we found no relationship between leptin expression in tumor tissues and gender. However, in a prospective study in Sweden, higher circulating leptin levels in men were associated with a higher the risk of colon cancer, but this was not the case for women (29). Similarly, in another study, leptin was associated with a higher risk of colon cancer only in men, but no association was observed in women (30). A Norwegian study also found a positive correlation between circulating leptin levels and colon cancer risk in men (31). Conversely, a collaborative Japanese cohort study (32) and Women's Health Initiative (WHI) cohort study (33) reported that women with higher leptin concentrations had a higher risk of developing colorectal cancer. Finally, one meta-analysis of six prospective studies found that the higher the leptin concentration was, the higher the risk of colorectal cancer (34).

A univariate Cox proportional risk regression model analysis showed that leptin expression level, smoking history, $\mathrm{T}$ stage, and $\mathrm{N}$ stage had influence on the longterm survival risk of patients. Among these, $\mathrm{T}$ stage and $\mathrm{N}$ stage had been recognized as evaluation factors. Smoking history was also a fairly well-acknowledged independent risk factor for lung cancer. The current results demonstrated that leptin level was not an independent factor for lung adenocarcinoma prognosis, but it was in consistent with
T stage of the tumors. While $T$ stage reflects the number and size of tumor lesions, which is closely related to the proliferation ability of tumor cells. It was speculated that leptin may affect the prognosis of patients by affecting the proliferative capacity of lung adenocarcinoma.

Circulating leptin can directly act on tumor cells, such as those of the breast, colon, prostate, or other malignant tumors. However, a recent meta-analysis showed that plasma leptin concentration had no significant effect on the survival rate and survival time of lung cancer patients (18). It is possible that the presence of a special functional structure, the blood-air barrier in the lung because of which leptin in the serum could not act directly on lung epithelial cells. The presence of this special structure of the blood-air barrier makes leptin act on lung cancer cells in a different manner from the above tumors, resulting in the aforementioned plasma leptin concentration having no significant impact on lung cancer patient's survival and survival time. Therefore, we speculate that leptin may promote proliferation of lung cancer cells through the autocrine and is likely to promote proliferation by similar mechanisms to that of serum leptin on other cancers. The present study, it was predicted by bioinformatics that the expression level of $L E P$ genes in lung adenocarcinoma was consistent with that of CDK2, cyclin D1, and other cyclins, which are important regulatory proteins at the G1/S checkpoint, and leptin may play an important role in pushing cell cycle across the G1/S checkpoint. This suggests that leptin may play a crucial role in the genesis and development of tumor proliferation.

In the current study, flow cytometry analysis of apoptosis showed that leptin expression was negatively correlated with apoptotic activity, which suggests that leptin plays an antiapoptotic role in lung adenocarcinoma cells. As was shown by previous reports, antiapoptotic effect of leptin has also been observed in breast cancer.

Bioinformatic analysis analyzing the tumor genome sequencing data of the 524 lung adenocarcinoma patients from TCGA predicted that leptin had a positive regulating effect on the PI3K/AKT/mTOR signaling pathway, and a negative regulating effect on the $P 53$ signaling pathway. We identified a batch of genes whose expression levels were significantly correlated with that of leptin in lung adenocarcinoma specimens.

The LEP gene is closely related to some important signaling molecules in the two signaling pathways, including PI3K, CCND1 (cyclin D1), LC3, MEK, ERK, CDK2, NF$\kappa B$, etc. These signaling factors strictly regulate cell proliferation, apoptosis, cycle, autophagy, and a series of 
biological functions closely related to tumor proliferation. Meanwhile, the $P I 3 K / A K T / m T O R$ signaling pathway is also closely connected with the $p 53$ signaling pathway via the signaling molecule, $M D M 2$. The function of $p 53$ is negatively regulated by the signal axis of $P I 3 K-A K T$ $M D M 2-P 53$. We found that the genes in the two signaling pathways were generally consistent with the $L E P$ expression Therefore, we can infer that $L E P$ secreted by lung cancer cells promotes the proliferation of lung adenocarcinoma cells by regulating the activity of its own $P I 3 K / A K T / m T O R$ and $p 53$ signaling pathways.

In order to verify the above phenomenon at the level of molecular mechanism, the effects of leptin expression levels in H1299 and A549 cells on key signaling molecules in the $P I 3 K / A K T / m T O R$ signaling pathway and $p 53$ signaling pathway were detected by western blotting and immunofluorescence staining. The results are in accord with previous results. It could be inferred that manifested a promoting effect on the proliferation of lung adenocarcinoma cells, which was similar to that of exogenous leptin on the proliferation of other tumor cells. In terms of mechanism, we found that the endogenous $L E P$ gene of lung adenocarcinoma has a positive regulatory relationship with its own $P I 3 K / A K T / m T O R$ signaling pathway, and a strong negative regulatory relationship with $p 53$ signaling pathway. It simultaneously activates the $M A P K / E R K$ pathway and $N F-k B$ signaling pathway, thus accelerating the cycle of lung adenocarcinoma cell proliferation and inhibiting cell apoptosis, which, together, accelerate the growth of lung cancer cells. Lung adenocarcinoma cells may regulate the PI3K/AKT/ $m T O R$ and $p 53$ signaling pathways through the expression of endogenous LEP gene, thus promoting their own proliferation. To our knowledge, this is the first study to provide evidence for this specific mechanism in lung adenocarcinoma.

The current study enriched the theoretical basis of the role of leptin as an important hormone in physiological and pathological processes. On the basis of previous studies, we known that leptin not only promotes tumor development as a serum hormone, but also acts on NSCLC cells in an autocrine manner to promote their proliferation, and leading to tumor progression and poor long-term prognosis. The findings of this study are helpful to provide new molecular targets for the diagnosis, treatment and prognosis of NSCLC. This study also has limitations, such as lack of in vivo experiments and small sample size of clinical cases. These deficiencies limit the discussion of the application value of leptin and should therefore be moderated in future studies.

\section{Conclusions}

Autocrined leptin was observed in the majority of NSCLC cases, which could serve as an auxiliary prognostic factor for NSCLC patients. Autocrined leptin had a promoting effect on the proliferation of NSCLC cells. Autocrined leptin promotes NSCLC proliferation probably though positively regulating the $P I 3 K / A K T / m T O R$ signaling pathway and negatively regulate the $P 53$ signaling pathway.

\section{Acknowledgments}

Funding: This work was supported by grants from the Natural Science Foundation of Liaoning province, China (20180550693).

\section{Footnote}

Reporting Checklist: The authors have completed the MDAR checklist. Available at http://dx.doi.org/10.21037/atm-207482

Data Sharing Statement: Available at http://dx.doi. org/10.21037/atm-20-7482

Conflicts of Interest: All authors have completed the ICMJE uniform disclosure form (available at http://dx.doi. org/10.21037/atm-20-7482). The authors have no conflicts of interest to declare.

Ethical Statement: The authors are accountable for all aspects of the work in ensuring that questions related to the accuracy or integrity of any part of the work are appropriately investigated and resolved. This study conformed to the provisions of the Declaration of Helsinki (as revised in 2013). The study was approved by the Ethics Committee of the First Affiliated Hospital of Dalian Medical University (No.: PJ-KS-KY-2021-39), and all participants signed written informed consent forms.

Open Access Statement: This is an Open Access article distributed in accordance with the Creative Commons Attribution-NonCommercial-NoDerivs 4.0 International License (CC BY-NC-ND 4.0), which permits the noncommercial replication and distribution of the article with 
the strict proviso that no changes or edits are made and the original work is properly cited (including links to both the formal publication through the relevant DOI and the license). See: https://creativecommons.org/licenses/by-nc-nd/4.0/.

\section{References}

1. Wood DE, Kazerooni EA, Baum SL, et al. Lung Cancer Screening, Version 3.2018, NCCN Clinical Practice Guidelines in Oncology. J Natl Compr Canc Netw 2018;16:412-41.

2. Vanbrabant T, Fassnacht $M$, Assie G, et al. Influence of hormonal functional status on survival in adrenocortical carcinoma: systematic review and meta-analysis. Eur J Endocrinol 2018;179:429-36.

3. Jerzak KJ, Duska L, MacKay HJ. Endocrine therapy in endometrial cancer: An old dog with new tricks. Gynecol Oncol 2019;153:175-83.

4. Conroy MJ, Dunne MR, Donohoe CL, et al. Obesityassociated cancer: an immunological perspective. Proc Nutr Soc 2016;75:125-38.

5. Lee $\mathrm{CH}$, Woo YC, Wang Y, et al. Obesity, adipokines and cancer: an update. Clin Endocrinol (Oxf) 2015;83:147-56.

6. Wei L, Li K, Pang X, et al. Leptin promotes epithelialmesenchymal transition of breast cancer via the upregulation of pyruvate kinase M2. J Exp Clin Cancer Res 2016;35:166.

7. Zhang Y, Proenca R, Maffei M, et al. Positional cloning of the mouse obese gene and its human homologue. Nature 1994;372:425-32.

8. Momken I, Chabowski A, Dirkx E, et al. A new leptinmediated mechanism for stimulating fatty acid oxidation: a pivotal role for sarcolemmal FAT/CD36. Biochem J 2017;474:149-62.

9. Barone I, Giordano C, Bonofiglio D, et al. Leptin, obesity and breast cancer: progress to understanding the molecular connections. Curr Opin Pharmacol 2016;31:83-9.

10. Herrera-Covarrubias D, Coria-Avila GA, FernándezPomares C, et al. Obesity as a risk factor in the development of cancer. Rev Peru Med Exp Salud Publica 2015;32:766-76.

11. Percik R, Stumvoll M. Obesity and cancer. Exp Clin Endocrinol Diabetes 2009;117:563-6.

12. El-Masry OS, Al-Sakkaf K, Brown BL, et al. Differential crosstalk between the AMPK and PI3K/AKT pathways in breast cancer cells of differing genotypes: Leptin inhibits the effectiveness of AMPK activation. Oncol Rep 2015;34:1675-80.
13. Chen C, Chang YC, Lan MS, et al. Leptin stimulates ovarian cancer cell growth and inhibits apoptosis by increasing cyclin D1 and Mcl-1 expression via the activation of the MEK/ERK1/2 and PI3K/AKT signaling pathways. Int J Oncol 2013;42:1113-9.

14. Suman S, Kallakury BV, Fornace AJ, et al. Protracted upregulation of leptin and IGF1 is associated with activation of PI3K/AKT and JAK2 pathway in mouse intestine after ionizing radiation exposure. Int J Biol Sci 2015;11:274-83.

15. El Homsi M, Ducroc R, Claustre J, et al. Leptin modulates the expression of secreted and membrane-associated mucins in colonic epithelial cells by targeting PKC, PI3K, and MAPK pathways. Am J Physiol Gastrointest Liver Physiol 2007;293:G365-73.

16. Calgani A, Delle Monache S, Cesare P, et al. Leptin contributes to long-term stabilization of HIF- $1 \alpha$ in cancer cells subjected to oxygen limiting conditions. Cancer Lett 2016;376:1-9.

17. Fan YL, Li XQ. Expression of leptin and its receptor in thyroid carcinoma: distinctive prognostic significance in different subtypes. Clin Endocrinol (Oxf) 2015;83:261-7.

18. Tong X, Ma Y, Zhou Q, et al. Serum and tissue leptin in lung cancer: A meta-analysis. Oncotarget 2017;8:19699-711.

19. Anar C, Deniz D, Erol S, et al. Are serum leptin levels a prognostic factor in advanced lung cancer. Bratisl Lek Listy 2017;118:13-6.

20. Feng H, Liu Q, Zhang N, et al. Leptin promotes metastasis by inducing an epithelial-mesenchymal transition in A549 lung cancer cells. Oncol Res 2013;21:165-71.

21. Karatas F, Yalcin B, Sahin S, et al. The significance of serum leptin level in patients with early stage nonsmall cell lung cancer. J Cancer Res Ther 2017;13:204-7.

22. Carpagnano GE, Spanevello A, Curci C, et al. IL-2, TNFalpha, and leptin: local versus systemic concentrations in NSCLC patients. Oncol Res 2007; 16:375-81.

23. Li Y, Geng J, Wang Y, et al. The role of leptin receptor gene polymorphisms in determining the susceptibility and prognosis of NSCLC in Chinese patients. J Cancer Res Clin Oncol 2012;138:311-6.

24. Molfino A, Iannace A, Colaiacomo MC, et al. Cancer anorexia: hypothalamic activity and its association with inflammation and appetite-regulating peptides in lung cancer. J Cachexia Sarcopenia Muscle 2017;8:40-7.

25. Askari S, Salehi R, Zarghami N, et al. The anticancer effects of biodegradable nanomagnetic dual natural components on the leptin gene expression in lung cancer. Artif Cells Nanomed Biotechnol 2016;44:1753-63. 
26. Song CH, Liao J, Deng $\mathrm{ZH}$, et al. Is leptin a predictive factor in patients with lung cancer. Clin Biochem 2014;47:230-2.

27. Duru S, Sönmez Z, Saygideğer Y, et al. The relationship between stage and tumor type and serum leptin level and leptin expression on tumor tissue in lung cancer. Tuberk Toraks 2011;59:427-8.

28. Guo T, Zhao S, Wang P, et al. YB-1 regulates tumor growth by promoting MACC1/c-Met pathway in human lung adenocarcinoma. Oncotarget 2017;8:48110-25.

29. Stattin P, Palmqvist R, Söderberg S, et al. Plasma leptin and colorectal cancer risk: a prospective study in Northern Sweden. Oncol Rep 2003;10:2015-21.

30. Hardwick JC, Van Den Brink GR, Offerhaus GJ, et al. Leptin is a growth factor for colonic epithelial cells.

Cite this article as: Wang J, Zhou F, Li F, Wang B, Hu Y, Li X. Autocrined leptin promotes proliferation of non-small cell lung cancer (NSCLC) via PI3K/AKT and $p 53$ pathways. Ann Transl Med 2021;9(7):568. doi: 10.21037/atm-20-7482
Gastroenterology 2001;121:79-90.

31. Stattin P, Lukanova A, Biessy C, et al. Obesity and colon cancer: does leptin provide a link. Int J Cancer 2004;109:149-52.

32. Tamakoshi K, Toyoshima H, Wakai K, et al. Leptin is associated with an increased female colorectal cancer risk: a nested case-control study in Japan. Oncology 2005;68:454-61.

33. Ho GY, Wang T, Gunter MJ, et al. Adipokines linking obesity with colorectal cancer risk in postmenopausal women. Cancer Res 2012;72:3029-37.

34. Joshi RK, Kim WJ, Lee SA. Association between obesity-related adipokines and colorectal cancer: a casecontrol study and meta-analysis. World J Gastroenterol 2014;20:7941-9. 